\title{
Relationships between Genetic Diversity and Fusarium Toxin Profiles of Winter Wheat Cultivars
}

\author{
Tomasz Góral $^{1 *}$, Kinga Stuper-Szablewska², Maciej Buśko², Maja Boczkowska ${ }^{3}$, Dorota Walentyn-Góral ${ }^{1}$, \\ Halina Wiśniewska ${ }^{4}$ and Juliusz Perkowski \\ ${ }^{1}$ Department of Plant Pathology, Plant Breeding and Acclimatization Institute - National Research Institute, Radzików, 05- \\ 870 Błonie, Poland \\ ${ }^{2}$ Department of Chemistry, Poznań University of Life Sciences, Wojska Polskiego 75, 60-625 Poznań, Poland \\ ${ }^{3}$ National Centre for Plant Genetic Resources, Plant Breeding and Acclimatization Institute - NRI, Radzików, 05-870 \\ Btonie, Poland \\ ${ }^{4}$ Institute of Plant Genetics, Polish Academy of Sciences, Strzeszyńska 34, 60-479 Poznań, Poland
}

(Received on March 17, 2015; Accepted on April 19, 2015)

Fusarium head blight is one of the most important and most common diseases of winter wheat. In order to better understanding this disease and to assess the correlations between different factors, 30 cultivars of this cereal were evaluated in a two-year period. Fusarium head blight resistance was evaluated and the concentration of trichothecene mycotoxins was analysed. Grain samples originated from plants inoculated with Fusarium culmorum and naturally infected with Fusarium species. The genetic distance between the tested cultivars was determined and data were analysed using multivariate data analysis methods. Genetic dissimilarity of wheat cultivars ranged between 0.06 and 0.78 . They were grouped into three distinct groups after cluster analysis of genetic distance. Wheat cultivars differed in resistance to spike and kernel infection and in resistance to spread of Fusarium within a spike (type II). Only B trichothecenes (deoxynivalenol, 3-acetyldeoxynivalenol and nivalenol) produced by $\boldsymbol{F}$. culmorum in grain samples from inoculated plots were present. In control samples trichothecenes of groups A (H-2 toxin, T-2 toxin, T-2 tetraol, T-2 triol, scirpentriol, diacetoxyscirpenol) and $B$ were detected. On the basis of Fusarium head blight assessment and analysis of trichothecene concentration in the grain relationships between morphological characters, Fusarium head blight resistance and mycotoxins in grain of wheat cultivars were examined. The results were used to create of matrices of distance between cultivars - for trichothecene concentration in

*Corresponding author.

Phone) +48-2273343636, FAX) +48-22725 4714

E-mail)t.goral@ihar.edu.pl inoculated and naturally infected grain as well as for FHB resistance Correlations between genetic distance versus resistance/mycotoxin profiles were calculated using the Mantel test. A highly significant correlation between genetic distance and mycotoxin distance was found for the samples inoculated with Fusarium culmorum. Significant but weak relationships were found between genetic distance matrix and FHB resistance or trichothecene concentration in naturally infected grain matrices.

Keywords : Fusarium culmorum, Fusarium head blight, genetic diversity, resistance, trichothecenes, wheat

Fusarium head blight (FHB) is a disease of wheat caused by numerous fungal patgogens from the genus Fusarium - mainly Fusarium graminearum and F. culmorum (Bottalico and Perrone, 2002; Miller, 1994; Snijders and Perkowski, 1990). The disease results in infection of spikes and contamination of a grain with Fusarium toxins such as deoxynivalenol (DON), nivalenol (NIV), zearalenone (ZEA) and many others (Bottalico and Logrieco, 1998; Chełkowski et al., 2001; Miller, 2008).

The studies on resistance of cultivars can be divided into several approaches such as genetic background, characterization of the yield structure and the concentration of toxins in grains. Attempts to consolidate different types of research have been carried out already for a long time (Bai et al., 2001; Mesterhazy et al., 1999; Mesterhazy, 2002; Miedaner, 1997). On the basis of the results, several theories were addressed concerning the mechanisms (types) of FHB resistance (Foroud and Eudes, 2009; Mesterhazy, 
1995). Different types of resistance were described or suggested. Initially, Schroeder and Christensen (1963) proposed two types: type I - resistance to initial infection; and type II - resistance to spread of the pathogen within the spike. These types were subsequently reported by other authors (Mesterhazy, 1995; Snijders and Kretching, 1992; Wang and Miller, 1988). Type III was defined as resistance to kernel infection and type IV as resistance to DON accumulation by inhibition of toxin synthesis or chemical modification of DON (e.g. DON-glucoside) (Berthiller et al., 2005; Foroud and Eudes, 2009; Mesterhazy, 1995; Miller and Arnison, 1986; Snijders and Perkowski, 1990; Wang and Miller, 1988). Type $\mathrm{V}$ is responsible for tolerance, i.e. the ability of a genotype to produce a higher yield than another at the same level of head blight severity or tolerance to DON manifested by low kernel damage despite high DON content (Foroud and Eudes, 2009; Mesterhazy et al., 1999; Mesterhazy, 1995). Different inoculation techniques as well as other assessment techniques are supposed to be used to precisely characterize genotype reaction to $\mathrm{Fu}-$ sarium head blight (Miedaner et al., 2003; Van Ginkel and Gilchrist, 2002).

However, none of the resistance mechanisms described have given complete picture of the complex nature of the FHB resistance. Hence, new approaches to the FHB resistance, such as metabolomics, genomics, etc have been emerged in recent years (Gunnaiah et al., 2012; Kumaraswamy et al., 2011; Rutkoski et al., 2012).

In our research we decided to use a slightly different approach to this issue, mainly to create matrices of genetic distance, FHB resistance distances and mycotoxin distance based on concentrations of trichothecenes in the grain of cultivars grown without treatment (controls) and inoculated with F. culmorum. Genetic distance between wheat cultivars was determined using inter-simple sequence repeat (ISSR) analysis. This type of molecular markers is characterized by high stability and reproducibility, abundance of genomic information, low operational cost and low labour intensity (Moreno et al., 1998; Shen et al., 2006). This technique was successfully used for the evaluation of genetic diversity and for fingerprinting varieties of species in the Gramineae family (Blair et al., 1999; Emel, 2010; Hai et al., 2007; Mitrofanova et al., 2009; Najaphy et al., 2011; Tams et al., 2004).

The purpose of the experiments was to determine the resistance of winter wheat cultivars by comparing the created matrices. In order to achieve this, statistical analysis was carried out based on the genetic distance relationships between FHB resistance and tolerance and accumulation of mycotoxins. Multivariate analysis and the Mantel test were applied for assessing the relationship between genetic distance and mycotoxin accumulation for 30 winter wheat cultivars naturally infected with Fusarium spp. and artificially inoculated with strains of F. culmorum.

\section{Materials and Methods}

Plant material. Thirty cultivars of winter wheat (Triticum aestivum L.) were evaluated. These cultivars were listed in the Polish National List of Agricultural Plant Varieties drawn up by the Research Centre for Cultivar Testing (COBORU http://www.coboru.pl). Cultivars 'Muszelka', Bogatka', 'Tonacja', 'Ostroga', 'Legenda' and 'Akteur' had the largest share in the wheat area in Poland according to the COBORU report (2012). The cultivars differed in the morphological characters and pedigree (Table 1).

Field experiment. Two field experiments were performed in 2010 and 2011 in the experimental field of the stateowned research institute - the Plant Breeding and Acclimatization Institute (PBAI) in Radzików, Central Poland (GPS coordinates: 52.211754, 20.631954).

Both experiments were established as a randomized block design. Wheat cultivars were sown in $1 \mathrm{~m}^{2}$ plots in six replicates/blocks. Three of them were a non-inoculated control and were located at about $15 \mathrm{~m}$ distance from inoculated blocks. Three Fusarium culmorum isolates producing deoxynivalenol (3ADON) (KF846, ZFR112), and nivalenol (NIV) (KF350) were applied for inoculum production. 3ADON chemotype isolates originated from Radzików, Poland and were isolated from wheat spikes (Ochodzki and Góral, 2006; Wiśniewska and Kowalczyk, 2005). The NIV chemotype isolate (IPO348) originated from the Netherlands and was isolated from a wheat spike (Snijders and Perkowski, 1990).

Isolates were incubated on autoclaved wheat kernels in glass flasks for about 1 week at $20^{\circ} \mathrm{C}$ in darkness and next exposed to near UV light under a 16 -h photoperiod for 3 weeks at $15^{\circ} \mathrm{C}$. The mycelium-colonized grain was air dried and stored in a refrigerator at $4^{\circ} \mathrm{C}$ until usage.

At the date of inoculation, the grain with Fusarium mycelium was suspended in tap water for $2 \mathrm{~h}$ and then filtered to obtain a conidial suspension. The suspensions from each of the three isolates were adjusted to $5 \times 10^{5}$ spores $/ \mathrm{ml}$ with the aid of a haemocytometer. Equal volumes of suspension were mixed.

Wheat spikes were sprayed with a spore suspension at anthesis at a rate of $100 \mathrm{ml} / \mathrm{m}^{2}$. Inoculations were performed individually on each plot at the beginning of anthesis, and repeated about 3 days later at full anthesis. 
Table 1. Characteristics of 30 cultivars of winter wheat

\begin{tabular}{|c|c|c|c|c|c|c|}
\hline No. & Cultivar & Pedigree & Country & $\begin{array}{c}\% \text { of wheat area } \\
2012\end{array}$ & $\begin{array}{l}\text { Quality } \\
\text { code }\end{array}$ & $\begin{array}{l}\text { Spike } \\
\text { type }\end{array}$ \\
\hline 1 & Akteur & $(87-308 \times$ Astron $) \times$ Astron & $\mathrm{DE}$ & 3.6 & $\mathrm{~A}$ & $\mathrm{AL}$ \\
\hline 2 & Alcazar & Charger $\times$ Lynx & PL & 1.2 & A & $\mathrm{AL}$ \\
\hline 3 & Anthus* & Greif $\times($ NFC2.192 $\times$ Zentos $)$ & $\mathrm{DE}$ & 0.0 & $\mathrm{~B}$ & $\mathrm{AL}$ \\
\hline 4 & Batuta & $($ Konsul $\times$ Korweta $) \times$ Kobra & PL & 1.2 & $\mathrm{~B}$ & $\mathrm{AL}$ \\
\hline 5 & Belenus & Cortez $\times$ ST $\times$ Hussar & FR & 0.1 & $\mathrm{C}$ & $\mathrm{AL}$ \\
\hline 6 & Bogatka & Urban $\times$ Kobra & PL & 5.6 & $\mathrm{~B}$ & $\mathrm{AL}$ \\
\hline 7 & Boomer & Haven $\times$ Torfrida $\times$ Transit & FR & 0.9 & A & $\mathrm{AL}$ \\
\hline 8 & Dorota & 94ST85 $\times$ Tambor & FR & 0.0 & $\mathrm{~B}$ & $\mathrm{AL}$ \\
\hline 9 & Figura & $($ Juma $\times$ G 664/26) $\times$ Pegassos & PL & 1.9 & $\mathrm{~A}$ & $\mathrm{AL}$ \\
\hline 10 & Garantus & Kris $\times$ Piko $\times$ Tambor & FR & 0.2 & $\mathrm{~B}$ & $\mathrm{AL}$ \\
\hline 11 & Jenga & $98 / 2574 \times$ Dekan & $\mathrm{DE}$ & 2.3 & $\mathrm{~B}$ & $\mathrm{AL}$ \\
\hline 12 & Kampana & CRT $9 \times$ Kris & PL & 0.8 & $\mathrm{C}$ & $\mathrm{AL}$ \\
\hline 13 & Kohelia & $($ Zentos $\times$ Kobra $) \times($ Euris $\times$ Kobra $)$ & PL & 0.5 & A & $\mathrm{AL}$ \\
\hline 14 & Legenda & N2015/85 × Astron & PL & 3.8 & A & $\mathrm{AL}$ \\
\hline 15 & Ludwig & Ares $\times$ Farmer & PL & 1.9 & A & $\mathrm{AL}$ \\
\hline 16 & Markiza & MIB $295 \times$ Zyta & PL & 0.3 & $\mathrm{C}$ & $\mathrm{AL}$ \\
\hline 17 & Meteor & Tarso $\times$ Contra $\times$ Hadmerslebener 91952-83 & $\mathrm{DE}$ & 0.7 & $\mathrm{~B}$ & $\mathrm{AL}$ \\
\hline 18 & Mewa & $(\mathrm{CHD} 756 / 78 \times$ FD 303 $) \times$ Gama & PL & 2.8 & $\mathrm{~B}$ & $\mathrm{~A}$ \\
\hline 19 & Mulan & Drifter $\times$ Maverick & $\mathrm{DE}$ & 2.5 & $\mathrm{~B}$ & $\mathrm{AL}$ \\
\hline 20 & Muszelka & Kris $\times$ Rubens & PL & 13.4 & $\mathrm{~B}$ & $\mathrm{AL}$ \\
\hline 21 & Naridana & Rektor $\times$ Kobra & PL & 2.9 & A & $\mathrm{AL}$ \\
\hline 22 & Nateja* & $($ Emika $\times$ EGRQ $) \times$ Kobra & PL & 0.0 & $\mathrm{~B}$ & $\mathrm{AL}$ \\
\hline 23 & Ostka Strzelecka & Gorbi $\times$ STH 48 & PL & 1.2 & A & A \\
\hline 24 & Ostroga & CEB $9504 \times$ Mewa & PL & 3.8 & A & $\mathrm{A}$ \\
\hline 25 & Slade** & Normann $\times[584-4-12 \times($ Haven $\times$ Consort $)]$ & FR & 0.0 & $\mathrm{~K}$ & $\mathrm{AL}$ \\
\hline 26 & Smuga & KOC $1688 \times$ CHD $498 / 84$ & PL & 0.6 & A & $\mathrm{AL}$ \\
\hline 27 & Sukces & Jubilatka $\times$ SMH 8134 & PL & 1.0 & A & $\mathrm{AL}$ \\
\hline 28 & Tonacja & Jubilatka $\times$ SMH 8134 & PL & 4.3 & A & $\mathrm{AL}$ \\
\hline 29 & Türkis & Tambor $\times$ Hadmerslebener 91639-89 & $\mathrm{DE}$ & 0.7 & A & $\mathrm{AL}$ \\
\hline 30 & Zyta & Jubilatka $\times$ SMH 8134 & PL & 3.0 & A & $\mathrm{AL}$ \\
\hline
\end{tabular}

Quality code: A - quality cultivar, B - bread cultivar, C - non-baking cultivar, K - biscuit cultivar. Head type: AL - awnless, A - awned. *,** - Cultivars deleted from the Polish National List in 2012 and 2013.

Inoculations were carried out in the evening, when relative air humidity was increasing. The disease was first rated at about 14 days after the last inoculation. Two ratings were done at an interval of 10 days. Fusarium head blight (FHB) was scored based on the mean percentage of blighted spikelets per infected spike (disease severity) and the percentage of infected spikes per plot (disease incidence). Fusarium head blight index was calculated as the combination of disease severity and disease incidence.

After ripening, 100 spikes were harvested manually from each plot and threshed with a laboratory thresher at a low wind speed to prevent loss of low-weight infected kernels. The percentage of Fusarium damaged kernels (FDK) was assessed visually by dividing the kernel sample into two categories: healthy kernels (plump, normal colour, no visual infection; slightly shrivelled of normal colour) and infected kernels showing different levels of damage (discoloured kernels of normal size or slightly shrivelled; pinkish-white, shrivelled kernels = 'tombstone') (Argyris et al., 2003).

Resistance to Fusarium spread (type II). Resistance to spread of Fusarium within a spike (type II) was assessed in four experiments under semi-controlled conditions. Experiments were conducted in foliar tents equipped with a mist irrigation system. Spikes of wheat were point in- 
oculated with a spore suspension of $F$. culmorum isolates of 3ADON chemotype - ZFR110 and ZFR112, and $F$. graminearum isolates of 3ADON chemotype - 1509 and ZFR15 (Buśko et al., 2014; Nielsen et al., 2012; Ochodzki and Góral, 2006). Prior to the experiment, aggressiveness of the isolates was tested on the set of wheat cultivars differing in FHB resistance (data not shown). Concentration of spore suspension was adjusted to $50,000 \mathrm{spores} / \mathrm{ml}$. A droplet of $50 \mu \mathrm{l}$ of suspension was injected into two flowers in the central spikelet of a spike using a self-refilling syringe. Five spikes per cultivar were inoculated with each isolate. After inoculation, high humidity was maintained. Spike infection with Fusarium was assessed 21 days after inoculation by calculation of the number of visually infected spikelets below the infection point.

Analysis of trichothecenes. Grain samples were analysed for the presence of trichothecenes according to Perkowski et al. (2007). Sub-samples (10 g) were extracted with acetonitrile/water (82:18) and cleaned up on a charcoal column (Celite 545/charcoal Draco G/60/activated alumina neutral 1:1:1 (w/w/w). Trichothecenes of group A ( $\mathrm{H}-2$ toxin, T-2 toxin, T-2 tetraol, T-2 triol, scirpentriol [STO], diacetoxyscirpenol [DAS]) were analysed as TFAA derivatives. To the dried sample the amount of $100 \mu$ of trifluoroacetic acid anhydride was added. After $20 \mathrm{~min}$, the reacting substance was evaporated to dryness under nitrogen. The residue was dissolved in $500 \mu \mathrm{l}$ of isooctane and $1 \mu \mathrm{l}$ was injected onto a gas chromatograph-mass spectrometer. Trichothecenes of group B (DON, NIV, 3-acetyldeoxynivalenol [3-AcDON], 15-acetyldeoxynivalenol [15-AcDON]) were analysed as TMS (trimethylsilyl ether) derivatives. To the dried extract the volume of $100 \mu \mathrm{TMSI} /$ TMCS (trimethylsilyl imidazole/trimethylchlorosilane, v/ v 100/1) mixture was added. After $20 \mathrm{~min}, 500 \mu \mathrm{l}$ of isooctane were added and the reaction was quenched with $1 \mathrm{ml}$ of water. The isooctane layer was used for the analysis and $1 \mu \mathrm{l}$ of the sample was injected on a GC/MS system. The analyses were run on a gas chromatograph (Hewlett Packard GC 6890) hyphenated to a mass spectrometer (Hewlett Packard 5972 A, Waldbronn, Germany), using an HP$5 \mathrm{MS} 0.25 \mathrm{~mm} \times 30 \mathrm{~m}$ capillary column. The injection port temperature was $280^{\circ} \mathrm{C}$, the transfer line temperature was $280^{\circ} \mathrm{C}$ and the analyses were performed with programmed temperatures, separately for group A and B trichothecenes. Group A trichothecenes were analysed using the following programmed temperatures: initial $80^{\circ} \mathrm{C}$ held for $1 \mathrm{~min}$, from $80^{\circ} \mathrm{C}$ to $280^{\circ} \mathrm{C}$ at $10^{\circ} \mathrm{C} / \mathrm{min}$, and the final temperature maintained for $4 \mathrm{~min}$. For group $\mathrm{B}$ trichothecenes the initial temperature was $80^{\circ} \mathrm{C}$, held for $1 \mathrm{~min}$, from $80^{\circ} \mathrm{C}$ to $200^{\circ} \mathrm{C}$ at $15^{\circ} \mathrm{C} / \mathrm{min}$ held $6 \mathrm{~min}$ and from $200^{\circ} \mathrm{C}$ to $280^{\circ} \mathrm{C}$ at $10^{\circ} \mathrm{C} / \mathrm{min}$, while the final temperature was maintained for $3 \mathrm{~min}$. The helium flow rate was held constant at $0.7 \mathrm{ml} /$ min. Quantitative analysis was performed in a single ion monitored (SIM) mode using the following ions for the detection of STO: 456 and 555; T-2 tetraol: 455 and 568; T-2 triol: 455 and 569 and 374; HT-2: 455 and 327; T-2: 327 and 401; DON: 103 and 512; 3-AcDON: 117 and 482; 15-AcDON: 193 and 482; NIV: 191 and 600. Qualitative analysis was performed in the SCAN mode (100-700 $\mathrm{amu})$. Recovery rates for the analysed toxins were as follows: STO $82 \pm 5.3 \%$; T-2 triol 79 $\pm 5.1 \%$; T-2 $86 \pm 3.8 \%$; T-2 tetraol $88 \pm 4.0 \%$; HT-2 91 $\pm 3.3 \%$; DON $84 \pm 3.8 \%$; 3 -AcDON $78 \pm 4.8 \%$; 15 -AcDON $74 \pm 2.2 \%$ and NIV $81 \pm 3.8 \%$. The limit of detection was $0.001 \mathrm{mg} / \mathrm{kg}$.

Estimation of genetic distance. Total genomic DNA was extracted from young, healthy leaf tissue using a Genomic Mini AX Plant kit (A\&A Biotechnology). Each cultivar was represented by one bulk sample. DNA quantity was determined spectrometrically (NanoDrop Spectrophotometer ND-1000) and its quality was assessed by electrophoresis on $1.5 \%$ agarose.

PCR amplification was carried out according to the Boczkowska and Tarczyk (2013) protocol. A set of eight ISSR primers (University of British Columbia) was used (Table 2) (Boczkowska and Tarczyk, 2013). The amplified products were separated and visualized using the capillary sequencer ABI 3130xl Genetic Analyzer. A $36 \mathrm{~cm}$ capillary array filled with polymer POP-7 was used. The length of fragments was assessed against the GeneScan1200 LIZ Size Standard (Applied Biosystems).

The length of the analysed fragments was determined using GeneMapper (Applied Biosystems) software and transformed into a binary character matrix where the presence of each reproducible fragment was scored as 1 , and its absence as 0 . Genetic distance for each pair of accessions was estimated according to the Dice formula (Dice, 1945) in FAMD 1.25 (Schlüter and Harris, 2006)

An analysis of marker performance was carried out. For each marker the percentage of polymorphic fragments and polymorphic information content (PIC) were calculated (Roldan-Ruiz et al., 2000). PIC was computed as $\mathrm{PIC}_{\mathrm{i}}=$ $2 \mathrm{f}_{\mathrm{i}}\left(1-\mathrm{f}_{\mathrm{i}}\right)$ where PIC $_{\mathrm{i}}$ is the polymorphic information content of marker ' $i$ ' and $f_{i}$ is the frequency of the amplified allele (Roldan-Ruiz et al., 2000).

Statistical analysis. Wheat cultivars were grouped according to their genetic dissimilarity using the agglomerative hierarchical clustering (AHC) method. Analysis was 
performed by means of the UPGMA (Unweighted pair group method with arithmetic mean) and Ward algorithms. Multivariate principal coordinate analysis (PCoA) was also applied for grouping of wheat cultivars.

Analysis of variance of FHB index and Fusarium damaged kernels (FDK) (incorporating Tukey's pairwise comparison of cultivars at the 5\% level of significance) was performed using the 'Mixed models' procedure of XLSTAT. Experimental years constituted a random factor in the model. For resistance of type II the 'ANOVA' procedure was applied with Fusarium isolate and cultivar as fixed factors and inoculated spike as a factor nested within cultivar.

The relationships between variables were investigated by Pearson correlation tests ('Correlation tests' procedure). Prior to analysis data which did not follow a normal distribution (flowering, all mycotoxins in inoculated and control samples) were log transformed to stabilize variances.

In order to group cultivars according to their resistance to FHB the k-means clustering method was used (' $\mathrm{k}$-means clustering' procedure). Groups of cultivars were formed based on the description of their resistance using FHBi, FDK, resistance of type II, DON, 3-AcDON, and NIV. The trace $(\mathrm{W})$ classification criterion was applied. As this criterion is sensitive to effects of scale, all variables were standardized prior to the analysis. Groups were visualised using discriminant analysis ['Discriminant Analysis (DA)' procedure].

Genetic dissimilarity between cultivars was correlated with the phenotypic dissimilarity matrix. The matrix was calculated using the Mahalanobis distance proximity measure for FHB index, FDK, 'type II' resistance, and DON, 3-AcDON and NIV concentrations in 2010 and 2011. Genetic dissimilarity was also correlated with dissimilarity in Fusarium toxins accumulation between cultivars. Two mycotoxin dissimilarity matrices were calculated for mycotoxin concentrations in inoculated and naturally infected samples from 2010 and 2011 using the Mahalanobis distance proximity measure. Correlations between matrices were calculated with the Mantel test ('Mantel test' procedure).

The statistical analysis was performed using Microsoft ${ }^{\circledR}$ Excel 2010/XLSTATC)-Pro (Version 2013.4.07, Addinsoft, Inc., Brooklyn, NY, USA).

\section{Results and Discussion}

Genetic distance. A total of 270 fragments were obtained using eight ISSR primers and $62.9 \%$ of them were polymorphic. The range of polymorphic fragments for each primer was $0.48-0.83$. The average number of fragments and polymorphic fragments per primer was 33.75 and 21.25 , respectively, and it was much higher than observed in the previous studies for wheat ISSR (Carvalho et al., 2009; Najaphy et al., 2011). This is undoubtedly the result of using high-resolution capillary electrophoresis instead of the commonly used agarose gels. The average value of PIC was moderate (0.21). Maximum PIC was obtained for UBC 834 (0.34), while the minimum value was demonstrated by UBC 856 (0.14). Comparable results were obtained for wheat (Najaphy et al., 2011 ), oat (Boczkowska and Tarczyk, 2013; Boczkowska et al., 2014) and goatgrass (Thomas and Bebeli, 2010). For more details see Table 2.

Genetic dissimilarity of cultivars ranged between 0.06 ('Anthus' vs. 'Belenus') and 0.78 ('Zyta' vs. 'Muszelka') with the average equal to 0.39 . The mean value is much lower than obtained for 172 European winter wheat elite lines by SSR and SNP markers (Würschum et al., 2013). This resulted from the fact that in the cited article lines and cultivars came from more diverse market than one country. Lower value of mean genetic distance in our study is also related to the presence of relatively large group of cultivars with similar genetic make-up as it is clear from cluster analysis and principal coordinate analysis graphs (Figs. 1 and 2). At the same time, higher diversity of cultivars derived by Polish breeding companies was noted in compari-

Table 2. ISSR primers and marker performance

\begin{tabular}{cllccc}
\hline Primer name & Sequence ${ }^{\prime} \rightarrow 3^{\prime}$ & Dye & Number of fragments & \% polymorphic & PIC \\
\hline UBC 807 & (AG)8T & 6-FAM & 54 & 68.5 & 0.23 \\
UBC 825 & (AC)8T & 6-FAM & 28 & 71.5 & 0.22 \\
UBC 834 & (AG)8YT & VIC & 61 & 65.6 & 0.32 \\
UBC 841 & (GA)8YC & VIC & 21 & 47.6 & 0.15 \\
UBC 856 & (AC)8YA & NED & 27 & 51.9 & 0.14 \\
UBC 857 & (AC)8YG & NED & 42 & 50.0 & 0.17 \\
UBC884 & HBH(AG)7 & PET & 14 & 64.3 & 0.23 \\
UBC 885 & BHB(GA)7 & PET & 23 & 82.6 & 0.24 \\
\hline
\end{tabular}




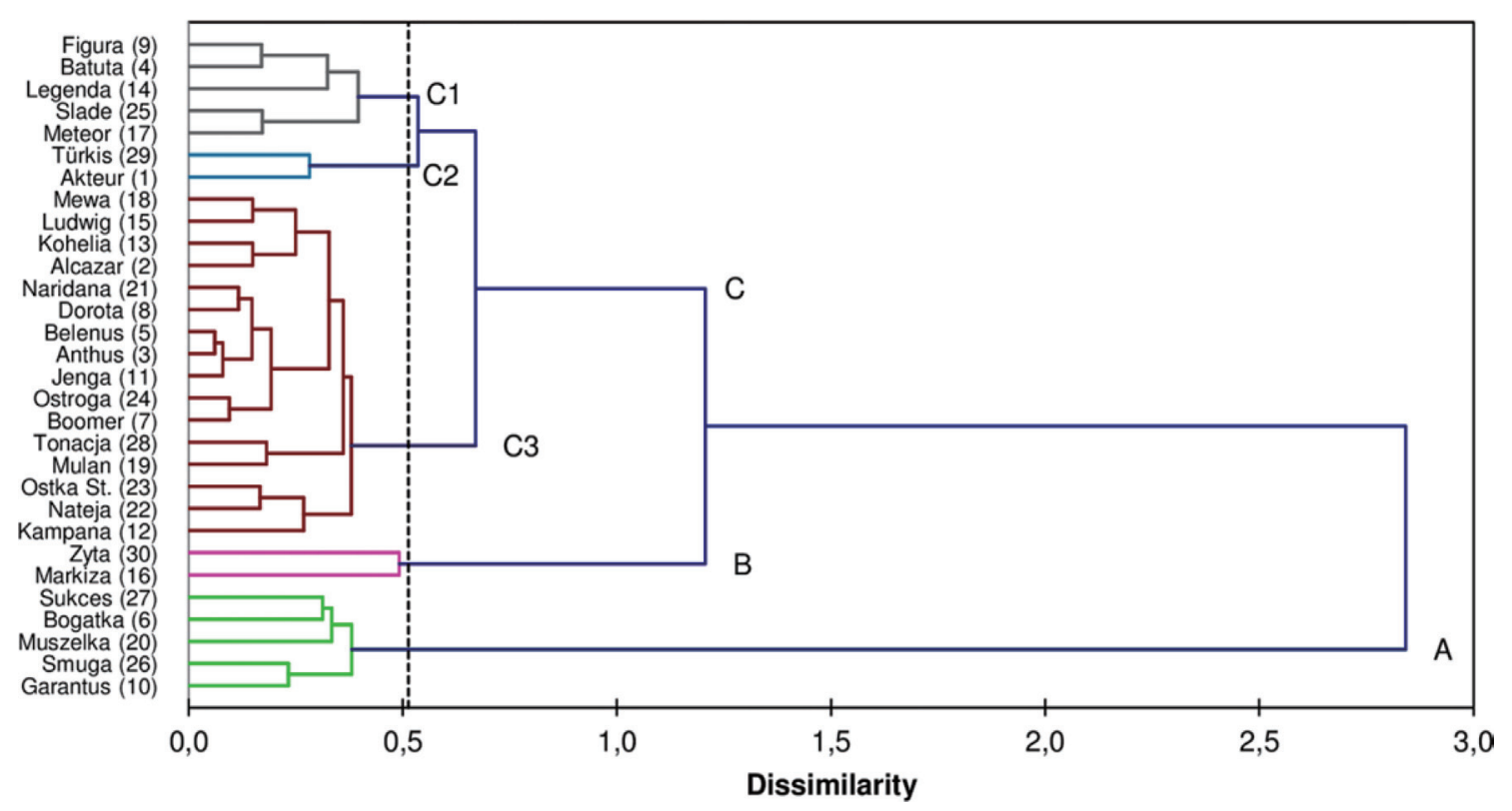

Fig. 1. Dendrogram resulting from ISSR-based genetic distance analysis of 30 cultivars of winter wheat, estimated with the Dice genetic similarity coefficient. Cluster analysis was performed using the Ward algorithm. Cultivar numbers correspond to those in Table 1.

son with the foreign ones ( 0.45 and 0.28 respectively). Of course, this might be the direct result of over-representation of indigenous forms in the tested material but it could also indicate greater richness of well adopt to local climatic condition Polish breeding materials. In general, range of genetic distance among authorised advanced cultivars is specific to the individual countries. Thus the maximum genetic distance of Polish cultivars is higher than obtained for Egyptian and Greek ones (Abdellatif and AbouZeid, 2011), comparable to the Croatian, Pakistani and Chinese cultivars (Maric et al., 2004; Zeb et al., 2009; Zhang et al., 2011) or lower than European elite lines (Würschum et al., 2013). Crops improvement is directly related to genetic diversity, which in wheat had been dramatically narrowed in 1960s and since then has been steadily increasing due to modern breeding (Sears, 1981; van de Wouw et al., 2010). Therefore, incorporation of genetic diversity studies into biotic and abiotic stress resistance breeding became a standard.

Thirty wheat cultivars were grouped into three distinct groups after cluster analysis (AHC) of genetic distance (Fig. 1). The most distant cluster (A) consisted of five cultivars: 'Bogatka', 'Garantus', 'Muszelka', 'Smuga', 'Sukces'. Two cultivars formed the next cluster (B) - 'Markiza' and 'Zyta'. The last 23 cultivars were grouped in the third cluster (C). This cluster could be further divided into subclusters: $\mathrm{C} 1$ - grouping five cultivars: 'Figura', 'Batuta', 'Legenda', 'Slade', 'Meteor'; C2 - grouping 2 cultivars: 'Turkis' and 'Akteur', and C3 - grouping the remaining 16

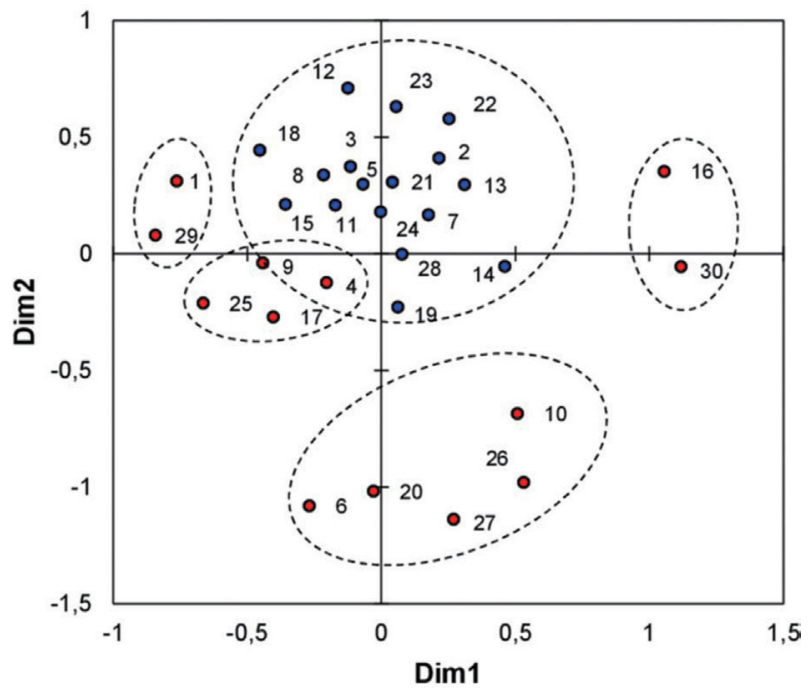

Fig. 2. Principal coordinate analysis based on genetic dissimilarity among 30 cultivars of winter wheat, estimated with the Dice genetic similarity coefficient. Groups corresponding to those identified by cluster analysis marked with circles. Cultivar numbers correspond to those in Table 1.

cultivars. A similar pattern was obtained through principal coordinate analysis (Fig. 2).

Only a weak relationship between the genetic distance and pedigree was observed. For example, three cultivars, 'Sukces', 'Tonacja' and 'Zyta', were selected from the same cross but were grouped in three distant clusters. 
Greater convergence of genetic distance and the pedigree of these three cultivars was presented by SSR markers (Stępień et al., 2007). In contrast, cultivars 'Zyta' and 'Markiza' sharing a common pedigree were grouped in the same cluster (Table 1). 'Markiza' was selected from a cross with 'Zyta' as parentage. Fernandez et al. (2002) analysed phylogenetic relationships of 16 barley cultivars from different countries, with a known pedigree. Grouping of cultivars agreed very well with their growth habit (spring vs. winter) and spike type (2-row vs. 6-row). However, regarding cultivar pedigree, there was no such clear grouping. Some cultivars with a common pedigree were grouped in different clusters, while conversely cultivars not related were grouped in the same cluster. In this research, only winter type cultivars with the same spike type were studied. Only three cultivars were awned ('Mewa', 'Ostroga', and 'Ostka Strzelecka'). They were in the same large cluster $\mathrm{C} 3$, but were not closely related; despite that 'Mewa' is the parental form of 'Ostroga'.

Fernandez et al. (2002) stated that a weak relationship between pedigree and cultivar genetic similarity was the effect of selection in breeding programmes. Using different selection strategies for progenies of a common cross can create genetically distant cultivars. In a paper on European winter triticale, Tams et al. (2004) found significant genetic variation among breeding companies (15.3\%). It was much lower than variation within companies $(84.7 \%)$, but much higher than molecular variance due to breeding programmes for sugar beet $(2.6 \%)$, maize $(10.2 \%)$, or soybean (12.4\%).

Najaphy et al. (2011) evaluated genetic diversity in 30 Iranian wheat cultivars and breeding lines of wheat. They were more phenotypically variable than the cultivar set analysed in our research. The ISSR analysis grouped cultivars and lines in five clusters. No relation was observed between clusters and phenotypic character or geographic origin of wheat genotypes. Dashchi et al. (2012) found a high level of genetic similarity in a collection of Iranian bread wheat using ISSR markers. They concluded that wheat breeding programmes have narrowed the genetic basis of Iranian bread wheat germplasm. A different story was found for triticale cultivars (Emel, 2010). The author found that 11 cultivars were grouped according to their country of origin (Poland, Turkey, USA). On the other hand, two distinct clusters were formed by cultivars depending on the origin of seed material. The author explained this by occurrence of cross-pollination between cultivars. It is known that in triticale considerable outcrossing rates can occur.

Fusarium head blight resistance. Wheat cultivars dif- fered in their earliness, height and length of spike as well as in resistance to spike and kernel infection and in resistance of type II after inoculation with $F$. culmorum or F. graminearum isolates (Table 3 ).

The average FHB index was $18.1 \%$ (21.1\% in 2010 and $15.2 \%$ in 2011). It ranged from $8.5 \%$ (cv. 'Legenda') to $33.3 \%$ (cv. 'Muszelka'). Three cultivars were highly resistant to spike infection - 'Legenda', 'Dorota' and 'Akteur - and two were found highly susceptible - 'Muszelka' and 'Belenus'. The percentage of Fusarium damaged kernels was $25.2 \%$ on average (12.6\% in 2010 and $37.9 \%$ in 2011). It ranged from $14.9 \%$ (cv. 'Ostroga') to $36.8 \%$ (cv. 'Belenus'). The lowest FDK was found in 3 cultivars - 'Ostroga, 'Boomer' and 'Jenga'.

Differences in spike and kernel infection in two experimental years were the result of contrasting weather conditions (Table 4). In 2010, precipitation during heading and flowering was much higher than in 2011. It resulted in higher spike infection in 2010. However, FHB indexes in 2010 and 2011 correlated significantly $(r=0.607)$. Next, during FHB development precipitation was much higher in 2011 and was accompanied by lower daily temperature than in 2010. As a result, the FDK proportion was found 3 times higher in 2011 than in 2010. No significant correlation between FDK in 2010 and 2011 was found. A similar relationship was observed for Fusarium mycotoxins, which is described in the next subsection. Cowger et al. (2009) found that post-flowering moisture had a significant enhancing effect on FHB, FDK, DON, and percent infected kernels of wheat. Authors used mist irrigation system and tested different durations of misting. They concluded that increasing numbers of wet days after flowering were associated mainly with increased disease symptoms, which in turn resulted in yield reduction and increased DON level. Similarly, Xu et al. (2007) found that FHB symptoms and concentration of mycotoxins increased with increasing length of wetness period and temperature. Kriss et al. (2012) observed that several environmental variables were associated with disease severity, fungal biomass in grain, and mycotoxins. However, the magnitude of the correlations was not high. It is suggested, that also other factors might affect the FHB severity and mycotoxin concentration (Kriss et al., 2012).

The number of infected spikelets (type II resistance) was on average 2.95. It ranged from 1.52 (cv. 'Markiza') to 4.74 (cv. 'Kampana'). Four cultivars showed the highest resistance of type II - 'Markiza', 'Meteor', 'Legenda' and 'Mulan'. The lowest level of this resistance was found in three cultivars - 'Belenus', 'Türkis', and 'Kampana'. The cultivar 'Muszelka', having the most infected heads in the 
Table 3. Resistance of winter wheat cultivars to Fusarium head blight after inoculation with Fusarium culmorum isolates

\begin{tabular}{|c|c|c|c|c|c|c|c|}
\hline No. & Cultivar & 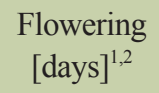 & $\begin{array}{l}\text { Plant height } \\
{[\mathrm{cm}]^{2}}\end{array}$ & $\begin{array}{l}\text { Length of } \\
\text { spike }[\mathrm{cm}]^{2}\end{array}$ & $\begin{array}{l}\text { Type II resistance } \\
\text { [no. of spikelets] }\end{array}$ & $\begin{array}{c}\text { FHB index } \\
{[\%]^{2}}\end{array}$ & FDK $[\%]^{2}$ \\
\hline 14 & Legenda & 9.0 & 96.8 & 12.3 & 2.00 & 8.5 & 22.8 \\
\hline 8 & Dorota & 7.5 & 81.5 & 10.5 & 3.10 & 8.6 & 19.5 \\
\hline 1 & Akteur & 8.5 & 93.5 & 11.2 & 2.85 & 8.8 & 19.0 \\
\hline 22 & Nateja & 6.5 & 100.8 & 9.6 & 2.75 & 9.8 & 18.3 \\
\hline 17 & Meteor & 8.0 & 90.8 & 10.4 & 1.75 & 10.3 & 30.0 \\
\hline 27 & Sukces & 8.5 & 95.2 & 8.4 & 2.88 & 11.5 & 26.4 \\
\hline 28 & Tonacja & 7.5 & 92.8 & 9.2 & 2.45 & 12.8 & 33.4 \\
\hline 11 & Jenga & 7.5 & 80.7 & 9.6 & 3.29 & 13.2 & 17.1 \\
\hline 18 & Mewa & 6.0 & 87.2 & 8.4 & 2.42 & 13.7 & 18.5 \\
\hline 7 & Boomer & 7.0 & 94.3 & 9.8 & 2.70 & 14.0 & 15.9 \\
\hline 24 & Ostroga & 7.5 & 87.0 & 7.1 & 3.60 & 14.0 & 14.9 \\
\hline 23 & Ostka Strzelecka & 6.5 & 92.2 & 8.9 & 2.55 & 14.2 & 18.0 \\
\hline 3 & Anthus & 7.5 & 88.0 & 10.1 & 3.03 & 14.2 & 27.8 \\
\hline 30 & Zyta & 8.5 & 106.0 & 8.5 & 2.55 & 14.3 & 26.1 \\
\hline 13 & Kohelia & 6.5 & 89.8 & 9.3 & 3.55 & 15.0 & 24.2 \\
\hline 19 & Mulan & 6.5 & 90.3 & 9.6 & 2.00 & 15.8 & 29.0 \\
\hline 10 & Garantus & 7.5 & 83.7 & 9.2 & 2.50 & 16.2 & 21.6 \\
\hline 16 & Markiza & 6.5 & 94.0 & 10.6 & 1.52 & 20.2 & 28.8 \\
\hline 29 & Türkis & 6.5 & 85.5 & 9.2 & 4.70 & 21.8 & 31.6 \\
\hline 9 & Figura & 5.0 & 101.5 & 9.8 & 3.20 & 22.0 & 25.6 \\
\hline 25 & Slade & 8.0 & 71.8 & 9.0 & 2.88 & 22.5 & 18.0 \\
\hline 6 & Bogatka & 4.5 & 98.0 & 9.1 & 3.10 & 23.0 & 30.6 \\
\hline 15 & Ludwig & 6.5 & 107.2 & 10.0 & 2.40 & 23.3 & 32.8 \\
\hline 12 & Kampana & 7.5 & 67.7 & 8.0 & 4.74 & 25.7 & 26.4 \\
\hline 26 & Smuga & 4.5 & 98.5 & 10.2 & 3.69 & 26.3 & 30.9 \\
\hline 4 & Batuta & 5.5 & 95.0 & 10.6 & 2.85 & 26.3 & 27.0 \\
\hline 2 & Alcazar & 8.5 & 74.8 & 10.2 & 3.33 & 27.2 & 28.5 \\
\hline 21 & Naridana & 5.0 & 84.5 & 9.2 & 3.15 & 27.8 & 26.1 \\
\hline 5 & Belenus & 7.5 & 86.5 & 8.0 & 4.31 & 29.7 & 36.8 \\
\hline \multirow[t]{3}{*}{20} & Muszelka & 6.5 & 68.7 & 9.2 & 2.55 & 33.3 & 31.5 \\
\hline & Mean & 7.0 & 89.5 & 9.5 & 2.95 & 18.1 & 25.2 \\
\hline & Tukey's $\mathrm{HSD}_{0.05}$ & - & - & - & 1.44 & 3.6 & 6.4 \\
\hline
\end{tabular}

${ }^{1}$ Number of days from May $31 ;{ }^{2}$ average from two field experiments in 2010 and $2011 ;{ }^{3}$ average number of spikelets infected by four Fusarium isolates. Cultivar numbers correspond to those in Table 1. Cultivars sorted according to the FHB index value.

field experiments, showed medium resistance of type II.

Correlation of morphological characters of wheat cultivars with FHB resistance parameters revealed a significant negative effect of flowering time on FHB index (Table 5). Plant height did not correlate significantly with FHB index or 'type II' resistance, but a clear negative tendency was visible. The four shortest cultivars ('Kampana', 'Muszelka', 'Slade', 'Alcazar') were within the group of the highest infected cultivars, but the tallest cultivar, 'Ludwig', was also highly infected.

Coefficients were negative, showing slower disease development on spikes of taller cultivars. The lower infection of taller genotypes is mainly the result of morphology and different microclimate of a spike (Mesterhazy, 1995, 2002; Yan et al., 2011). However, higher susceptibility of short cultivars may result also from presence of the semidwarfing gene Rht-D1b (Rht2) (Miedaner and Voss, 2008; Kollers et al., 2013). Draeger et al. (2007) reported that this relationship is due to either linked genes conferring FHB susceptibility and/or a pleiotropic physiological effect of the dwarfing allele at $R h t D 1$ enhancing susceptibility. It was found that $R h t-D 1 b$ affected mainly type I resistance 
Table 4. Daily air temperatures and precipitation sums from May 15 to August 15 in 2010 and 2011 in the experimental site in Radzików. Averages of 2005-2013 included

\begin{tabular}{|c|c|c|c|c|c|c|}
\hline \multirow{2}{*}{$\frac{\text { Year }}{\text { Period }}$} & \multicolumn{3}{|c|}{ Air temperature $[\mathrm{C}]$} & \multicolumn{3}{|c|}{ Precipitation sum [mm] } \\
\hline & 2010 & 2011 & $\begin{array}{c}\text { Average } \\
2005-2013\end{array}$ & 2010 & 2011 & $\begin{array}{c}\text { Average } \\
2005-2013\end{array}$ \\
\hline May $16-31$ & 14.4 & 17.7 & 15.8 & 113.40 & 2.4 & 40.7 \\
\hline June $1-15$ & 19.0 & 19.8 & 17.2 & 38.20 & 20.6 & 29.5 \\
\hline June $16-30$ & 16.6 & 18.1 & 18.7 & 26.40 & 32.2 & 31.0 \\
\hline July $1-15$ & 22.3 & 18.0 & 20.3 & 35.20 & 158.0 & 44.4 \\
\hline July $16-31$ & 21.2 & 18.4 & 20.4 & 96.40 & 134.2 & 52.5 \\
\hline August $1-15$ & 21.9 & 18.8 & 19.4 & 10.40 & 113.2 & 52.2 \\
\hline
\end{tabular}

(incidence) rather than the type II resistance (spread of pathogen) (Srinivasachary et al., 2009). However, Kollers et al. (2013) found significant marker-trait associations of $R h t-D 1$ for both FHB incidence and FHB severity. The two most infected cultivars in our research had parents carrying Rht1-Dlb genes. These were the cultivar 'Muszelka' (dwarfing gene from cv. 'Rubens') and cv. 'Belenus' (dwarfing gene from cv. 'Hussar') (Holzapfel et al., 2008; Voss et al., 2008).

The FHB index significantly correlated with the FDK percentage (Table 5). Moderate correlation coefficients were the result of low variability in the FHB index and FDK proportion in the studied set of commercial wheat cultivars not carrying highly effective resistance genes. However, the majority of wheat cultivars registered and grown in Poland are less susceptible compared with e.g. UK cultivars (Kollers et al., 2013; Nicholson et al., 2008). In more diverse experimental populations these coefficients may be very high (Mesterhazy, 2002; Mesterhazy et al., 2008).

Type II' resistance (to pathogen spread within a spike) had a significant but low effect on FHB index score in the field experiments (Table 5). This suggests that FHB development in the field, spray inoculated experiments was determined also by other factors. These could be: resistance to initial infection (type I), flowering type (Skinnes et al., 2010), and plant height (described above). 'Type II' resistance was correlated with spike length, which however had no effect on FHB index under field conditions.

Fusarium toxin - inoculated samples. Trichothecenes of group A and B were detected in the wheat samples (Table 6). In grain samples from inoculated plots in both years, only B trichothecenes produced by $F$. culmorum were present. The mean DON content found in the wheat samples was $3.370 \mathrm{mg} / \mathrm{kg}(2.566 \mathrm{mg} / \mathrm{kg}$ in 2010 and $4.174 \mathrm{mg} / \mathrm{kg}$ in 2011). The highest content of DON $(7.635 \mathrm{mg} / \mathrm{kg})$ was detected in sample from the cultivar 'Turkis' $(5.504 \mathrm{mg} / \mathrm{kg}$ in 2010 and $9.766 \mathrm{mg} / \mathrm{kg}$ in 2011), while the lowest content was found in samples from the cultivar 'Jenga'- $1.587 \mathrm{mg} /$ $\mathrm{kg}(1.177 \mathrm{mg} / \mathrm{kg}$ in 2010 and $1.996 \mathrm{mg} / \mathrm{kg}$ in 2011). Additionally, the DON acetyl derivative $3-\mathrm{AcDON}$ was found at a low concentration of $0.272 \mathrm{mg} / \mathrm{kg}(0.206 \mathrm{mg} / \mathrm{kg}$ in 2010 and $0.339 \mathrm{mg} / \mathrm{kg}$ in 2011). No $15-\mathrm{AcDON}$ was detected, as only $3 \mathrm{ADON}$ chemotype isolates of $F$. culmorum were used for inoculations in the field. NIV concentration was also low at $0.354 \mathrm{mg} / \mathrm{kg}(0.206 \mathrm{mg} / \mathrm{kg}$ in 2010 and 0.448 $\mathrm{mg} / \mathrm{kg}$ in 2011). Concentrations of all B trichothecenes

Table 5. Relationships between morphological characters and Fusarium head blight resistance of 30 winter wheat cultivars. Averages from experiments in 2010 and 2011

\begin{tabular}{lccccc}
\multicolumn{1}{c}{ Variables } & $\begin{array}{c}\text { Log flowering } \\
{[\text { days] }}\end{array}$ & $\begin{array}{c}\text { Plant height } \\
{[\mathrm{cm}]}\end{array}$ & $\begin{array}{c}\text { Length of } \\
\text { spike [cm] }\end{array}$ & $\begin{array}{c}\text { Type II resistance } \\
\text { [no. of spikelets] }\end{array}$ & $\begin{array}{c}\text { FHB index } \\
{[\%]}\end{array}$ \\
\hline Plant height [cm] & -0.248 & & & & \\
Length of spike [cm] & 0.052 & 0.256 & & & \\
Type II resistance [no. of spikelets] & -0.129 & -0.353 & $\mathbf{- 0 . 4 5 0}$ & & $\mathbf{0 . 3 9 5}$ \\
FHB index [\%] & $\mathbf{- 0 . 4 6 8}$ & -0.336 & -0.226 & 0.110 & $\mathbf{0 . 5 5 6}$ \\
FDK [\%] & -0.219 & 0.098 & 0.036 & $\mathbf{0 . 5 3 6}$ \\
\hline
\end{tabular}

Values in bold are different from 0 with a significance level of $P \leq 0.05$. 
Table 6. Accumulation of Fusarium trichothecene toxins in grain of 30 winter wheat cultivars inoculated with $F$. culmorum (inoculated) or naturally infected with Fusarium fungi (control) collected in 2010 and 2011

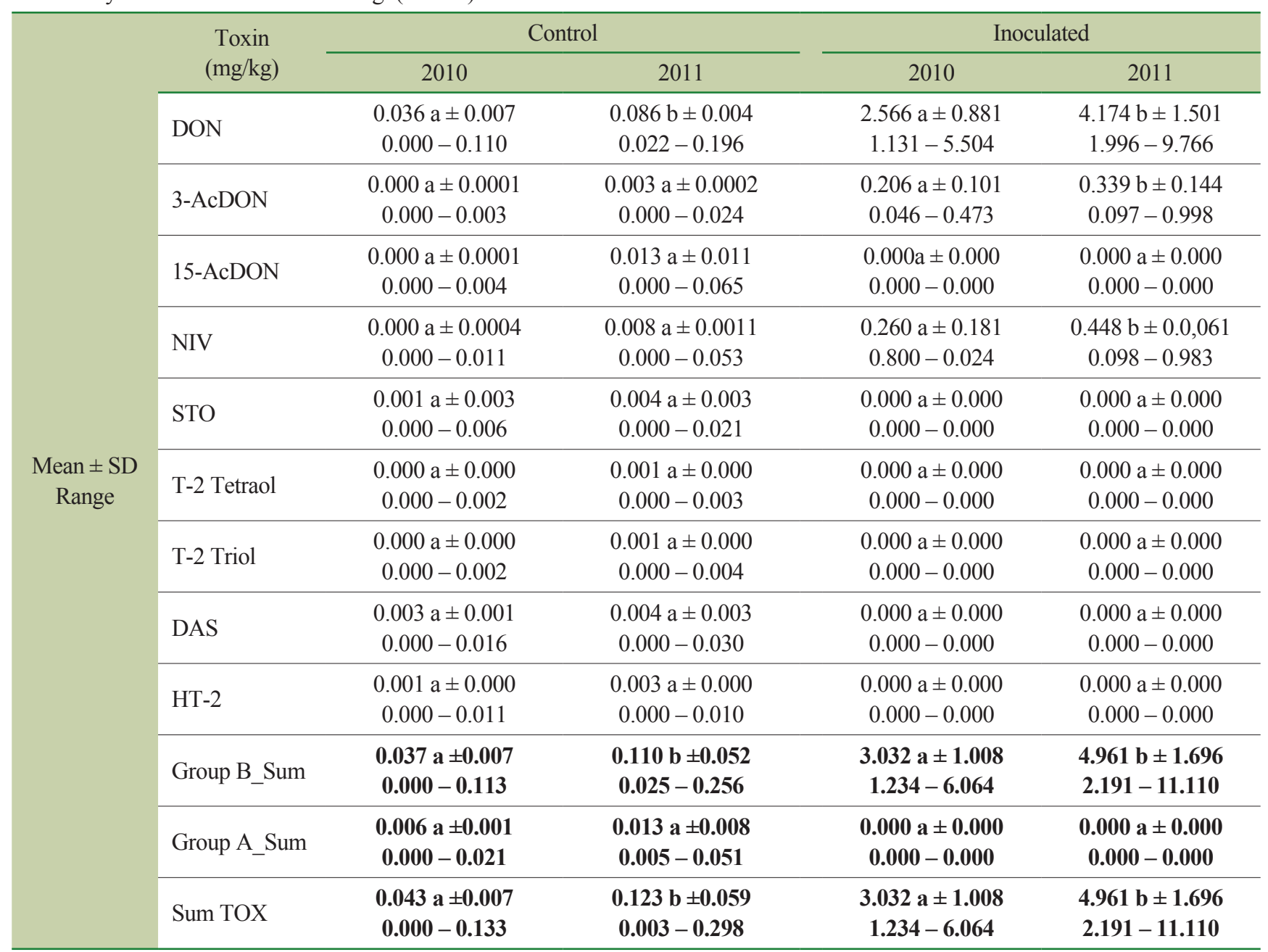

a, $\mathrm{b}$ - identical letters in rows denote a lack of significant differences with a significance level of $P=0.001$.

Table 7. Relationships between concentrations $(\mathrm{mg} / \mathrm{kg}$ ) of Fusarium toxins in grain of 30 wheat cultivars inoculated with $F$. culmorum in 2010 and 2011

\begin{tabular}{lccccc}
\hline \multicolumn{1}{c}{ Toxins $[\mathrm{mg} / \mathrm{kg}]$} & DON 2010 & 3-AcDON 2010 & NIV 2010 & DON 2011 & 3-AcDON 2011 \\
\hline 3-AcDON 2010 & $\mathbf{0 . 8 7 9}$ & & & & \\
NIV 2010 & $\mathbf{0 . 5 6 1}$ & $\mathbf{0 . 5 3 4}$ & & $\mathbf{0 . 6 8 7}$ & $\mathbf{0 . 6 9 2}$ \\
DON 2011 & $\mathbf{0 . 5 7 6}$ & & & $\mathbf{0 . 6 0 6}$ & $\mathbf{0 . 6 2 9}$ \\
3-AcDON 2011 & & & $\mathbf{0 . 6 0 6}$ \\
NIV2011 & & & & \\
\hline
\end{tabular}

Variables log transformed; values in bold are different from 0 with a significance level of $P \leq 0.05$.

were significantly higher in 2011 than in 2010 according to the Kruskal-Wallis test.

Fusarium toxin concentrations in inoculated grain samples from both experimental years correlated significantly (Table 7). Correlations between different B trichothecenes in 2010 as well as in 2011 were also significant. This sug- gests that genetic resistance to this group of toxins was present in studied wheat cultivars, despite the lack of alleles for resistance present in Chinese germplasm such as Sumai 3 (Fhb1) or Wangshuibai (Fhb2) etc. (Buerstmayr et al., 2009). It was confirmed in published papers on wheat resistance (Horevaj et al., 2011) and effects of application 
Table 8. Relationships between FHB resistance and accumulation of mycotoxins in grain of 30 wheat cultivars inoculated with $F$. culmorum. Averages from the experiments in 2010 and 2011

\begin{tabular}{lccccc}
\hline Variables & FHB index $[\%]$ & FDK $[\%]$ & DON $[\mathrm{mg} / \mathrm{kg}]^{1}$ & 3-AcDON $[\mathrm{mg} / \mathrm{kg}]^{1}$ & $\mathrm{NIV}[\mathrm{mg} / \mathrm{kg}]^{1}$ \\
\hline DON $[\mathrm{mg} / \mathrm{kg}]^{1}$ & $\mathbf{0 . 5 5 2}$ & $\mathbf{0 . 4 8 5}$ & & & \\
3-AcDON $[\mathrm{mg} / \mathrm{kg}]^{1}$ & 0.137 & 0.280 & $\mathbf{0 . 7 5 0}$ & $\mathbf{0 . 5 4 7}$ & $\mathbf{0 . 4 1 3}$ \\
NIV [mg/kg] & 0.075 & 0.156 & $\mathbf{0 . 9 8 7}$ & $\mathbf{0 . 8 1 6}$ & $\mathbf{0 . 5 4 1}$ \\
B trichothecenes $[\mathrm{mg} / \mathrm{kg}]^{1}$ & $\mathbf{0 . 4 9 8}$ & $\mathbf{0 . 4 6 8}$ & $\mathbf{0 . 9 8}$
\end{tabular}

Values in bold are different from 0 with a significance level $P \leq 0.05 ;{ }^{1}$ variables $\log$ transformed.

of purified DON and NIV to wheat spikes (Lemmens et al., 2008). Significant correlations were observed between FHB index and FDK vs. mycotoxin content (Table 8). The correlation of FHB symptoms and concentration of Fusarium toxins in grain in different studies is very variable. Coefficients ranged from low to medium to very high (Burlakoti et al., 2010; Miedaner and Perkowski, 1996; Miedaner, 1997; Mesterhazy et al., 1999, 2006, 2008; Tamburic-Ilincic et al., 2011). This is due to the strong impact of environmental conditions on mycotoxin production in the field experiments. As was reported e.g. by Lemmens et al. (2004) or Cowger and Arellano (2013), a DON level in a harvested grain was strongly modified by weather conditions. The same spike infection symptoms or kernel damage associated with different environmental conditions did not result in the same DON levels. Moreover, DON accumulated in grain can be leached from spikes, being a watersoluble compound (Gautam and Dill-Macky, 2012; Góral - unpublished; Perkowski et al., 2008). The other factor is heterogeneity of the populations tested. Narrow variability in the population (i.e. only medium resistant/susceptible genotypes without major FHB resistance genes) causes a stronger effect of the environment on the results (Mesterhazy et al., 2006). Large differences between genotypes give more stable results and higher correlations between symptoms and mycotoxin content, e.g. Mesterhazy (2002) or Mesterhazy et al. (2008). In this study the population of cultivars can be characterized as moderately resistant; thus relations between different types of resistance were less stable than could be expected from highly resistant genotypes like 'Sumai 3' or highly susceptible ones.

When analysing linear regressions of variables from Table 8, we found that some cultivars were far from the regression line. Figure 3 shows the relationship between FDK and DON concentration (log transformed). Kernels of the cultivar 'Belenus' were highly damaged by Fusarium $(\mathrm{FDK}=36.8 \%)$, but DON concentration in grain was low $(1.986 \mathrm{mg} / \mathrm{kg})$. Two other cultivars also show low DON content despite medium kernel damage - 'Jenga' and 'Meteor'.

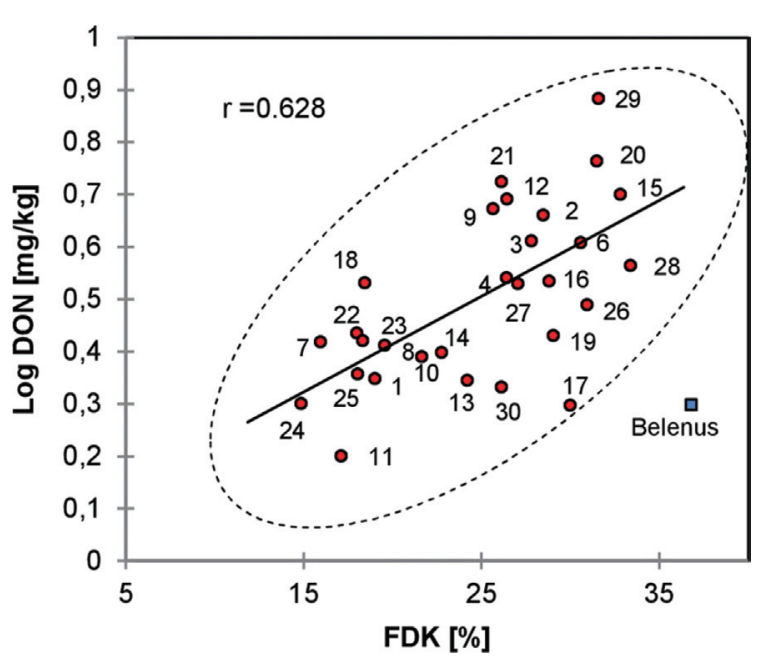

Fig. 3. Linear regression of FDK percentage versus DON concentration (log transformed) in grain of 29 cultivars. Cultivar 'Belenus' excluded from regression. Cultivar numbers correspond to those in Table 1.

The cultivar 'Belenus' probably carries the Rht $1-D 1 b$ gene inherited from the parental cv. 'Hussar'. As mentioned above, this gene is associated with increased susceptibility to spike infection. However, it seems that 'Belenus' possesses a mechanism of resistance to toxin accumulation (resistance type V) of unspecified mechanism - degradation, detoxification or inhibition (Foroud and Eudes, 2009). Detoxification of DON is a process of chemical modification of toxin in planta to the chemical form of reduced toxicity for the host. The only reported modification is glycosylation or conjugation of trichothecene to glucose (Berthiller et al., 2005; Boutigny et al., 2008). The resulting compound is DON-3-glucoside. It is less toxic to the plant and is not detected using routine procedures of trichothecenes analysis. The other mechanism - inhibition of toxin biosynthesis, may be triggered by compounds present in the kernel or induced as a response to the pathogen attack (Boutigny et al., 2008). Compounds with antioxidant properties, like phenolic compounds, peptides or carotenoids, as well as with pro-oxidant properties, like hydrogen per- 
oxide or linoleic acid-derived hydroperoxides are reported as affecting mycotoxin biostynthesis.

Correlations between DON, 3-AcDON and NIV were significant; however, coefficients for NIV were lower. We found that some cultivars deviated from linear regression and accumulated more NIV. These were low DON accumulating cultivars 'Meteor', 'Ostka Strzelecka' and 'Legenda' as well as high DON accumulating cultivars 'Batuta', 'Markiza' and 'Figura'. Miedaner and Reinbrecht (2001) found such deviation of some genotypes previously for wheat. As it was found by Lemmens et al. (2008) Fhbl resistance gene was effective in reduction of symptoms both after wheat inoculation with DON- or NIV-producing isolates. The same was observed by Toth et al. (2008) in the experiment including also wheat lines not possessing Fhbl gene. DON concentration in the spike was reduced by conjugating this toxin to glucose resulting in DON-3-glucoside (Lemmens et al., 2008). DON glycosylation was postulated by Lemmens et al. (2005) as main FHB resistance mechanisms, accompanied by other mechanisms like inhibition of toxin biosynthesis or cell wall thickening due to deposition of phenylpropanoids (Boutigny et al., 2008; Gunnaiah et al., 2012). Authors suggested possibility that $F h b 1$ encodes a glucosyl transferase that is effective against Fusarium strains that produce DON or similar trichothecenes. NIV concentrations did not differ between Fhb1 lines and nonFhb1 lines (Lemmens et al., 2008). Authors detected presence of NIV-glucoside but only at trace amounts. They hypothesised that the detoxification mechanisms of DON and NIV differed. This could partially explain differences in DON/NIV ratio for different cultivars in the present study.

$\mathrm{K}$-means analysis of data on FHB resistance and mycotoxins content grouped cultivars according to their FHB resistance of different types (Fig. 4, Table 9). Group (class) 1 , comprising 12 cultivars, could be characterised by low spike infection, low kernel damage and low Fusarium toxin content in grain. Cultivars in the group 2 had more susceptible spikes and higher kernel damage and accumulated more toxins than cultivars from group 1. The two groups did not differ in resistance of type II. Group 3 comprised

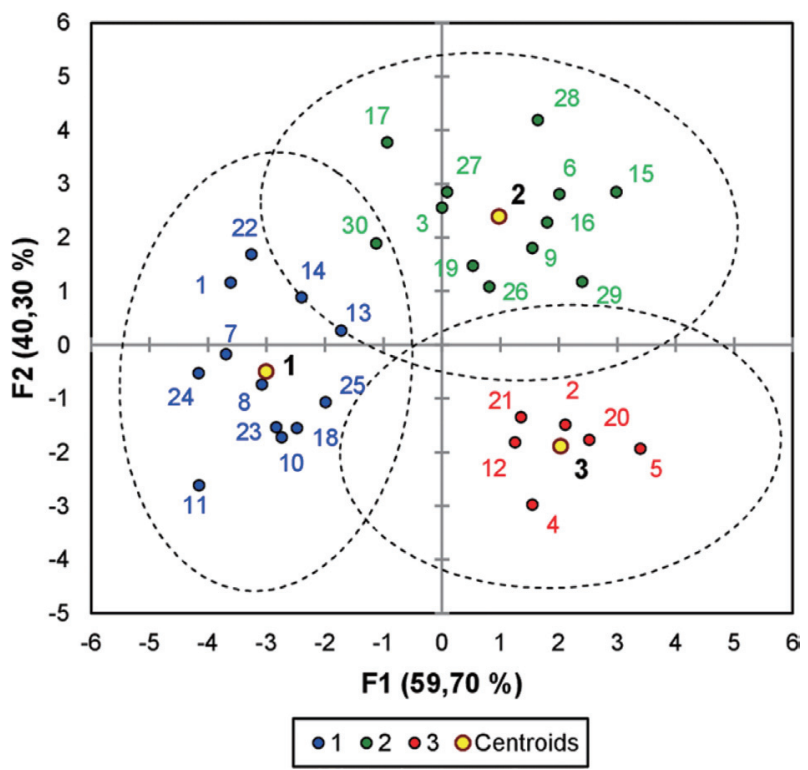

Fig. 4. Discriminant analysis based on Fusarium head blight (FHB), Fusarium damaged kernels (FDK), resistance of type 2 and mycotoxin accumulation in grain (DON, 3AcDON, NIV) of 30 cultivars of winter wheat inoculated with $F$. culmorum in the years 2010 and 2011. Classes (1, 2, 3) defined by k-means cluster analysis. Cultivar numbers correspond to those in Table 1.

the six most susceptible cultivars as regards spike infection and DON accumulation. However, they had similar FDK as cultivars in the group 2 .

Fusarium toxins - naturally infected samples. In grain samples naturally infected with Fusarium, trichothecenes of both groups A and B were detected (Table 6). The concentration of DON was the highest $-0.061 \mathrm{mg} / \mathrm{kg}$ on average $(0.036 \mathrm{mg} / \mathrm{kg}$ in 2010 and $0.086 \mathrm{mg} / \mathrm{kg}$ in 2011) and even up to $0.196 \mathrm{mg} / \mathrm{kg}$ for the grain sample of 'Kohelia' in 2011. DON was detected in 27 samples in 2010 and in all samples in 2011.

Amounts of other trichothecenes from group B were much lower. 15-AcDON was detected in six samples in 2010 and in 16 in 2011. 3-AcDON and NIV were detected

Table 9. Characteristics of cultivar classes created by k-means cluster analysis of FHB index, FDK, 'type II' resistance, and DON, 3-AcDON and NIV concentrations in 30 cultivars in 2010 and 2011

\begin{tabular}{cccccccc}
\hline Class & $\begin{array}{c}\text { No. of } \\
\text { cultivars }\end{array}$ & $\begin{array}{c}\text { FHB index } \\
{[\%]}\end{array}$ & FDK [\%] & $\begin{array}{c}\text { Type II resistance } \\
{[\text { no. of spikelets }]}\end{array}$ & $\begin{array}{c}\text { DON } \\
{[\mathrm{mg} / \mathrm{kg}]}\end{array}$ & $\begin{array}{c}3-\mathrm{AcDON} \\
{[\mathrm{mg} / \mathrm{kg}]}\end{array}$ & $\begin{array}{c}\text { NIV } \\
{[\mathrm{mg} / \mathrm{kg}]}\end{array}$ \\
\hline 1 & 12 & 13.2 & 19.0 & 2.85 & 2.434 & 0.208 & 0.285 \\
2 & 12 & 18.0 & 29.4 & 2.77 & 3.828 & 0.344 & 0.408 \\
3 & 6 & 28.3 & 29.4 & 3.49 & 4.326 & 0.256 & 0.385 \\
\hline Total/Mean & $\mathbf{3 0}$ & $\mathbf{1 8 . 1}$ & $\mathbf{2 5 . 2}$ & $\mathbf{2 . 9 5}$ & $\mathbf{3 . 3 7 0}$ & $\mathbf{0 . 2 7 2}$ & $\mathbf{0 . 3 5 4}$ \\
\hline
\end{tabular}


in single samples in 2010 and in five samples each in 2011. FUS-X was not detected. Concentrations of DON and $15-A c D O N$ were significantly higher in 2011 than in 2010 according to the Kruskal-Wallis test. More frequent presence of $15-A c D O N$ than $3 A c D O N$ is obvious given that in the species $F$. graminearum dominating in Poland 15-AcDON prevailed (Stępień et al., 2008).

Regarding A trichothecenes, concentration of DAS was the highest. It was $0.003 \mathrm{mg} / \mathrm{kg}$ on average $(0.003 \mathrm{mg} / \mathrm{kg}$ in both years), and up to $0.030 \mathrm{mg} / \mathrm{kg}$ in grain of 'Muszelka' in 2011. DAS was found in 24 grain samples in 2010 and in 18 in 2011. STO was detected in 12 and 16 samples in 2010 and 2011, respectively. HT-2 was present in 11 and 14 samples in 2010 and 2011, respectively, T-2 tetraol in 5 and 8 samples and T-2 triol in 1 and 5 samples in 2010 and 2011, respectively. T-2 toxin was not detected. No statistically significant differences were observed between concentrations of A trichothecenes in 2010 and in 2011 according to the Kruskal-Wallis test.

Presence and concentration of Fusarium toxins in naturally infected wheat are generally in accordance with data on occurrence of Fusarium species on wheat in Poland. According to the published data, the dominant species on wheat spikes and kernels was $F$. graminearum, with $F$. culmorum as the second species (Bottalico and Perrone, 2002; Chełkowski et al., 2012; Góral et al., 2012; Perkowski et al., 1990). In most samples, presence of DAS was detected. The main producers of this toxin are $F$. langsethiae, $F$. poae and F. sporotrichioides (Kokkonen et al., 2012; Schollenberger et al., 2007; Stenglein, 2009; Thrane et al.,

Table 10. Relationships between resistance to fungal spread (type II) after point inoculation and accumulation of mycotoxins in grain of 30 wheat cultivars naturally infected with Fusarium fungi

\begin{tabular}{lcc}
\hline Toxin & Correlation coefficient & $P$-values \\
\hline DON & $\mathbf{0 . 6 0 4}$ & $\mathbf{0 . 0 0 0}$ \\
3AcDON & -0.112 & 0.555 \\
15AcDON & $\mathbf{0 . 4 5 3}$ & $\mathbf{0 . 0 1 2}$ \\
NIV & $\mathbf{0 . 4 5 3}$ & $\mathbf{0 . 0 1 2}$ \\
Group B_Sum & $\mathbf{0 . 6 4 2}$ & $\mathbf{0 . 0 0 0}$ \\
STO & $\mathbf{0 . 5 5 9}$ & $\mathbf{0 . 0 0 1}$ \\
T-2 Tetraol & 0.336 & 0.070 \\
T-2 Triol & 0.309 & 0.096 \\
DAS & 0.272 & 0.145 \\
HT-2 & 0.348 & 0.060 \\
Group A_Sum & $\mathbf{0 . 5 1 8}$ & $\mathbf{0 . 0 0 3}$ \\
Sum TOX & $\mathbf{0 . 6 4 7}$ & $\mathbf{0 . 0 0 0}$ \\
\hline
\end{tabular}

Variables log transformed.
2004). Occurrence of $F$. langsethiae on wheat in Poland was confirmed in 2008, but this species was found mainly in Northern Poland (Góral et al., 2011; Góral - unpublished; Łukanowski et al., 2008). The other DAS producer $F$. poae was frequently isolated from wheat spikes and kernels in Poland (Góral et al., 2011; Goliński et al., 1996). This is a weak pathogen of cereal spikes, but is widespread on wheat in Poland (Góral et al., 2011; Vogelgsang et al., 2008; Góral - unpublished). F. poae is also known as an NIV producer (Schollenberger et al., 2006; Thrane et al., 2004). Despite this we detected NIV in only a few samples and no traces of this toxin in other samples. In Poland NIV was found primarily in oats infected by $F$. poae (Perkowski et al., 1997). Edwards et al. (2012) found that the correlation of NIV concentration in oat grain and $F$. poae DNA was highly significant but only accounted for $9 \%$ of the variance, indicating that $F$. poae was partly responsible for nivalenol present within UK oats but was not the main producer. Other NIV producers infecting wheat, namely $F$. graminearum and F. culmorum of NIV chemotype, are not frequent in Poland. Stępień et al. (2008) found that only $12 \%$ of $F$. graminearum isolates displayed the NIV chemotype. DON content highly correlated with NIV $(r=0.604)$ as well as the group A trichothecene STO ( $r=0.653)$. Regarding trichothecenes of group A, concentration of HT-2 was correlated significantly with T-2 tetraol and T-triol toxins $(r=0.765$ and $r=0.729)$. This correlation shows that these toxins were produced by the same species infecting wheat spikes (Thrane et al., 2004). A highly significant correlation between DON and STO was also found. Samples containing the highest concentration of DON were also contaminated with STO. Probably spikes/plots infected by DON producers were also infected by STO producing species (Perkowski et al., 2003; Schollenberger et al., 2007).

Concentration of trichothecenes A and B did not correlated significantly with $\mathrm{FHB}$ index or with proportion of FDK after inoculation with $F$. culmorum. Similarly, there were no correlations with concentrations of trichothecenes $\mathrm{B}$ in inoculated samples. However, we found significant relationships between resistance of type II (to fungal spread) and concentration of trichothecenes B - DON, 15-AcDON and NIV (Table 10). Moreover, type II resistance correlated with trichothecene A -STO and sum of toxins of this group. Resistance to Fusarium spread within the wheat head is mainly associated with resistance to DON and related trichothecene B - NIV. During the FHB pathogenesis trichothecenes are produced by Fusarium to cause necrosis of wheat tissue which next is colonised by Fusarium mycelium (Gunnaiah et al., 2012). The major FHB resistance gene Fhb1which explains up to $60 \%$ of variation for type 
II resistance was also responsible for reduction of DON or NIV accumulation (Buerstmayr et al., 2009; Lemmens et al., 2008). At high infection pressure, after spray inoculation with F. culmorum the effect of type II resistance on head infection or DON content was low. In our field experiments natural pressure of Fusarium infection was low, which is obvious from a low concentration of toxins in control samples. Under these conditions, resistance of type II was reducing infection with different Fusarium species, visible from lower concentration of trichothecene toxins.

Genetic distance versus resistance/mycotoxin profiles. The Mantel test was used to calculate the correlation between matrices of genetic dissimilarity and phenotypic dissimilarity. We found a significant correlation of genetic distance between cultivars vs. FHB resistance between cultivars (FHB index, FDK, 'type II' resistance, DON, 3-AcDON, NIV; separately from 2010 and 2011) (Fig. 5).

The correlation coefficient calculated using the Mantel test was low. However, it should be taken into consideration that the ISSR marker used in this research shows genetic diversity of wheat cultivars. Significance of correlation of two matrices may suggest that there is some linkage between the ISSR marker used and gene/genes conferring resistance to FHB, earliness or plant height. As shown by Reddy et al. (2002), ISSR markers were successfully used for gene tagging or used in marker-assisted selection for agronomic traits.

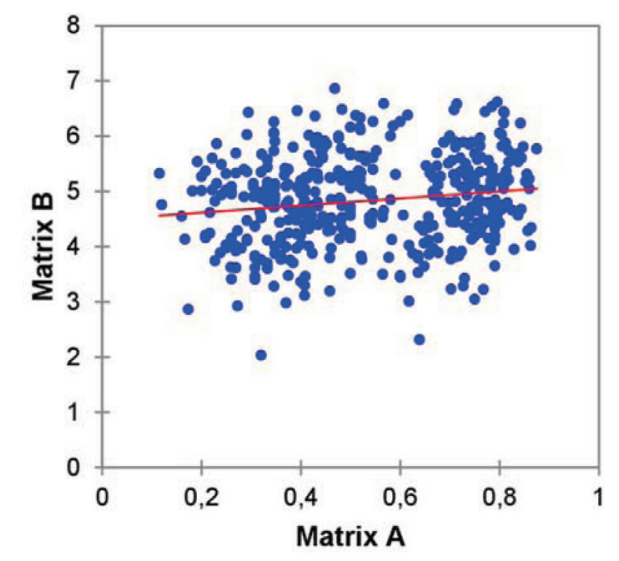

Next, the Mantel test was applied to calculate the correlation between matrices of genetic dissimilarity and mycotoxin accumulation dissimilarity. Regarding noninoculated samples, no relationship was observed between genetic distance between cultivars and concentration of mycotoxins produced by Fusarium species naturally infecting spikes $[\mathrm{r}(\mathrm{AB})=0.068]$. This could be the effect of low spike infection of control plots. Toxin occurrence and concentration in grain depended mainly on environmental factors, such as microclimate of individual plots and availability of inoculum of certain Fusarium species (Champeil et al., 2004; Leplat et al., 2013; Schuster and Ellner, 2008). Despite this, we found some significant correlations when analysing separately matrices for trichothecenes A and B (Fig. 6).

The Mantel test applied to data for samples from $F$. culmorum inoculated plots revealed a significant correlation between two matrices (Fig. 6). The correlation coefficient between two matrices was twice as high as for all phenotypic characters (Fig. 5). It seems that the strongest linkage was found between the ISSR marker used and gene/genes conferring resistance to accumulation of group B trichothecenes.

Genetic variability revealed by ISSR markers was significantly related to variability of mycotoxin concentration in grain. Thus PCoA analysis was performed to prove that cultivars would be similarly grouped. Wheat cultivars were organized into six distinct groups (Fig. 7). Most of the

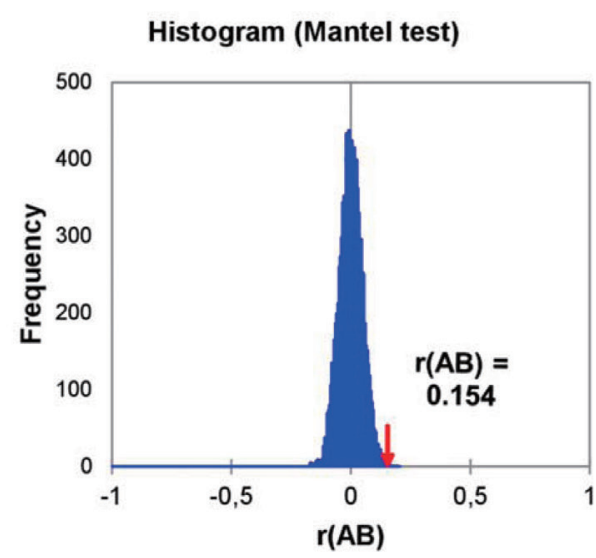

Mantel test / Two-tailed test:

\begin{tabular}{cc}
\multicolumn{3}{c}{ Mantel test / Two-tailed test: } \\
\hline $\mathrm{r}(\mathrm{AB})$ & 0.154 \\
$\mathrm{p}$-value (Two-tailed) & 0.002 \\
alpha & 0.05 \\
\hline
\end{tabular}

Fig. 5. Histogram and matrix of correlation of the Mantel test assessing the relationship between genetic distance and phenotypic distance (FHBi, FDK, 'type II' resistance, DON, 3AcDON, NIV) for 30 winter wheat cultivars inoculated with Fusarium culmorum isolates. 
Control - trichothecenes A
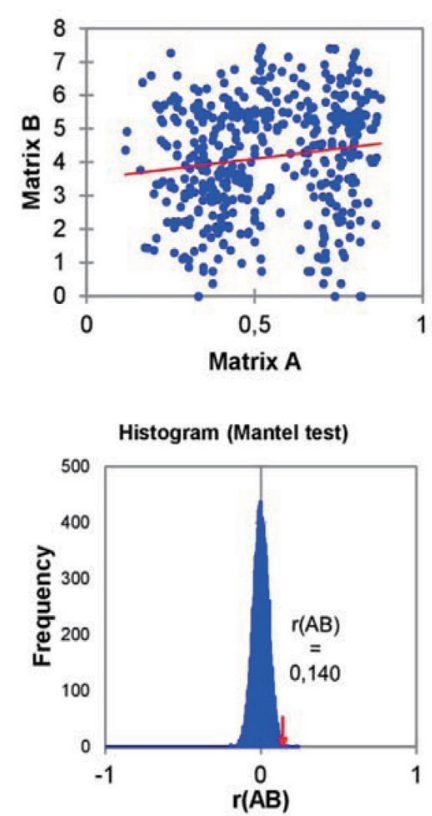

Control - trichothecenes B
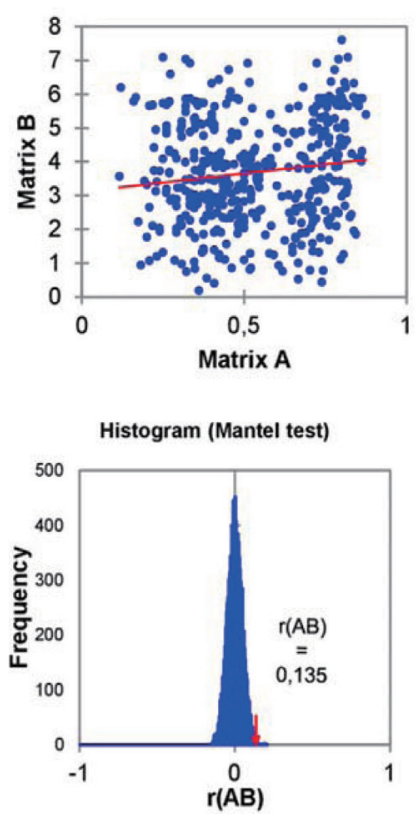

Inoculated - trichothecenes B
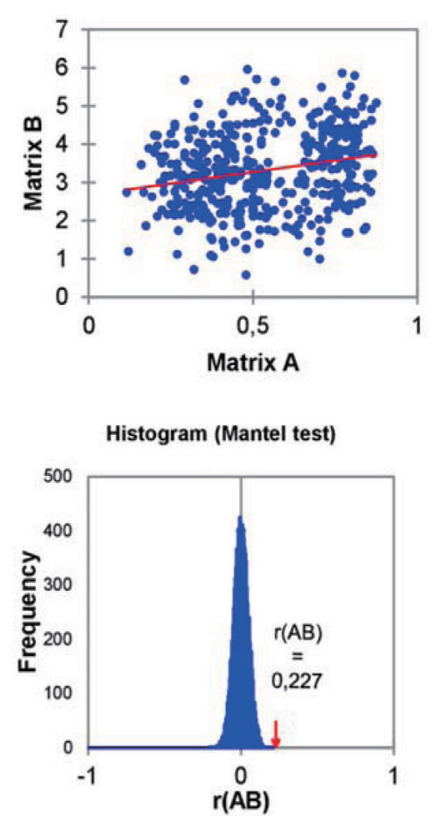

Mantel test / Two-tailed test

\begin{tabular}{lrrr}
\hline $\mathrm{r}(\mathrm{AB})$ & $0.140 \mathrm{r}(\mathrm{AB})$ & $0.135 \mathrm{r}(\mathrm{AB})$ & 0.227 \\
$\mathrm{p}$-value (Two-tailed) & 0.004 p-value (Two-tailed) & $0.005 \mathrm{p}$-value (Two-tailed) & $<0.0001$ \\
alpha & 0.05 alpha & 0.05 alpha & 0.05 \\
\hline
\end{tabular}

Fig. 6. Histograms and matrices of correlation of the Mantel test assessing the relationship between genetic distance and mycotoxin accumulation for 30 winter wheat cultivars naturally infected with Fusarium spp. (Control - trichothecenes A and B) and inoculated with Fusarium culmorum isolates (Inoculated - trichothecenes B) in the years 2010 and 2011.

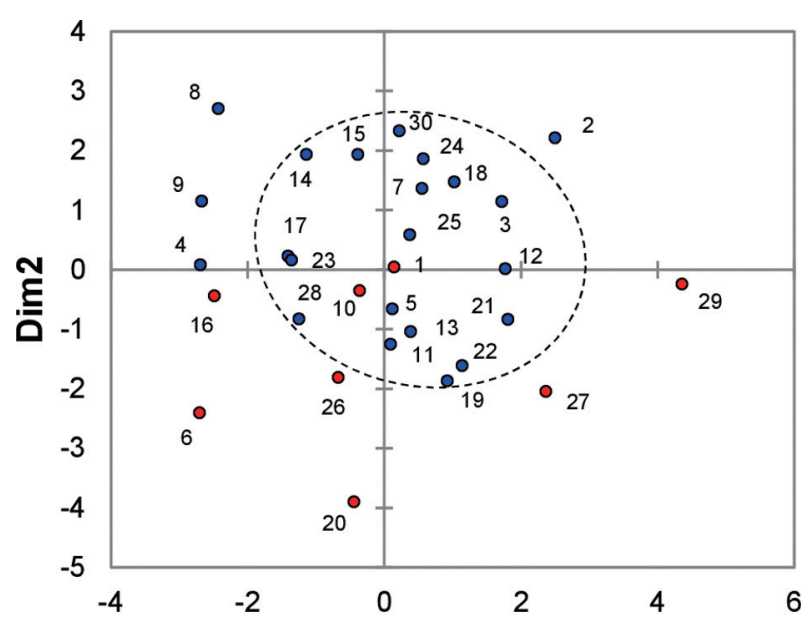

Fig. 7. Principal coordinate analysis based on matrix of distances in DON, 3AcDON and NIV concentration in grain of 30 cultivars of winter wheat inoculated with $F$. culmorum in the years 2010 and 2011. Cultivar numbers correspond to those in Table 1.

cultivars (21) fell into one large group, which was similar to the grouping according to the genetic distance (Fig. 2).
However, only six cultivars were distant from this large group based on both PCoA analyses. These were: 'Bogatka' (6), 'Markiza' (16), 'Muszelka' (20), 'Sukces' (27), 'Smuga' (26) and 'Turkis' (29). Two cultivars, which were placed in cluster $\mathrm{C} 1$ according to AHC analysis (Fig. 1), were also distant from the large group. These were: 'Batuta' (4), and 'Figura' (9).

Several quantitative trait loci (QTLs) for resistance to trichothecenes (DON) were identified in wheat (Buerstmayr et al., 2009). However, most of them were found in exotic (non-European) sources of resistance such as Chinese 'Sumai 3', Japanese 'Nobeokabozu' or Brazilian 'Frontana'. There is limited knowledge about European wheat gene pools in terms of FHB resistance genes/QTLs (Gervais et al., 2003; Miedaner et al., 2011; Schmolke et al., 2008). Published results revealed the presence of low effect QTLs associated with FHB resistance. DON accumulation was not evaluated in these studies, but from research on Chinese resistance sources it is known that some QTLs are a gene complex consisting of specific gene(s) controlling type II FHB resistance by detoxification of DON (Handa et 
al., 2008). Our initial results suggest the possibility for use of ISSR for gene tagging and in marker-assisted selection for FHB resistance.

\section{Acknowledgments}

This work was partly supported by the National Science Centre in Poland (project no. NCN 2704/B/PO1/2011/40.

\section{References}

Abdellatif, K. F. and AbouZeid, H. M. 2011. Assessment of genetic diversity of Mediterranean bread wheat using Randomly Amplified Polymorphic DNA (RAPD) markers. J. Genet. Eng. Biotechnol. 9:157-163.

Argyris, J., Sanford, D. Van and TeKrony, D. 2003. Fusarium graminearum infection during wheat seed development and its effect on seed quality. Crop Sci. 43:1782-1788.

Bai, G-H., Plattner, R., Desjardins, A., Kolb, F. and McIntosh, R.A. 2001. Resistance to Fusarium head blight and deoxynivalenol accumulation in wheat. Plant Breed. 120:1-6.

Berthiller, F., Dall'Asta, C., Schuhmacher, R., Lemmens, M., Adam, G. and Krska, R. 2005. Masked mycotoxins: determination of a deoxynivalenol glucoside in artificially and naturally contaminated wheat by liquid chromatography-tandem mass spectrometry. J. Agric. Food. Chem. 53:3421-3425.

Blair, M. W., Panaud, O. and McCouch, S. R. 1999. Inter-simple sequence repeat (ISSR) amplification for analysis of microsatellite motif frequency and fingerprinting in rice (Oryza sativa L.). Theor. Appl. Genet. 98:780-792.

Boczkowska, M. and Tarczyk, E. 2013. Genetic diversity among Polish landraces of common oat (Avena sativa L.). Genet. Resour. Crop Evol. 60:2157-2169.

Boczkowska, M., Nowosielski, J., Nowosielska, D. and Podyma, W. 2014. Assessing genetic diversity in 23 early Polish oat cultivars based on molecular and morphological studies. Genet. Resour. Crop Evol. 61:927-941.

Bottalico, A. and Perrone, G. 2002. Toxigenic Fusarium species and mycotoxins associated with head blight in small-grain cereals in Europe. Eur. J. Plant Pathol. 108:611-624.

Bottalico, A. and Logrieco, A. 1998. Toxigenic Alternaria species of economic importance. In: Mycotoxins in Agriculture and Food Safety, eds. by K. K. Sinha, D. Bhatnager, pp. 65-108. Marcel Dekker Inc., New York, USA.

Boutigny, A. L., Richard-Forget, F. and Barreau, C. 2008. Natural mechanisms for cereal resistance to the accumulation of $\mathrm{Fu}$ sarium trichothecenes. Eur. J. Plant Pathol. 121:411-423.

Buerstmayr, H., Ban, T. and Anderson, J. A. 2009. QTL mapping and marker-assisted selection for Fusarium head blight resistance in wheat: a review. Plant Breed. 128:1-26.

Burlakoti, R. R., Mergoum, M., Kianian, S. F. and Adhikarim, T. B. 2010. Combining different resistance components enhances resistance to Fusarium head blight in spring wheat.
Euphytica 172:197-205.

Buśko, M., Kulik, T., Ostrowska, A., Góral, T. and Perkowski, J. 2014. Quantitative volatile compound profiles in fungal cultures of three different Fusarium graminearum chemotypes. FEMS Microbiol. Lett. 359:85-93.

Carvalho, A., Lima-Brito, J., Maçãs, B. and Guedes-Pinto, H. 2009. Genetic diversity and variation among botanical varieties of old Portuguese wheat cultivars revealed by ISSR assays. Biochem. Genet. 47:276-294.

Champeil, A., Doré, T. and Fourbet, J. 2004. Fusarium head blight: epidemiological origin of the effects of cultural practices on head blight attacks and the production of mycotoxins by Fusarium in wheat grains. Plant Sci. 166:1389-1415.

Chełkowski, J., Gromadzka, K., Stępień, Ł., Lenc, L., Kostecki, M. and Berthiller, F. 2012. Fusarium species, zearalenone and deoxynivalenol content in preharvest scabby wheat heads from Poland. World Mycotoxin J. 5:133-141.

Chełkowski, J., Perkowski, J., Grabarkiewicz-Szczęsna, J., Kostecki, M. and Goliński, P. 2001. Toxigenic fungi and mycotoxins in cereal grains and feeds in Poland. In: Occurrence of Toxigenic Fungi and Mycotoxins in Plants, ed. by A. Logrieco, pp. 111-130. Food and Feeds in Europe. European Commission, COST Action 835, EUR 19695.

Cowger, C. and Arellano, C. 2013. Fusarium graminearum infection and deoxynivalenol concentrations during development of wheat spikes. Phytopathology 103:460-471.

Cowger, C., Patton-Özkurt, J., Brown-Guedira, G. and Perugin, L. 2009. Post-anthesis moisture increased Fusarium head blight and deoxynivalenol levels in North Carolina winter wheat. Phytopathology 99:320-327.

Dashchi, S., Mandoulakani, B. A., Darvishzade, R. and Bernousi, I. 2012. Molecular similarity relationships among Iranian bread wheat cultivars and breeding lines using ISSR markers. Not. Bot. Horti. Agrobo. 40:254-260.

Dice, L. 1945. Measures of the amount of ecologic association between species. Ecology 26:297-302.

Draeger, R., Gosman, N., Steed, A., Chandler, E., Thomsett, M., Srinivasachary, Schondelmaier, J., Buerstmayr, H., Lemmens, M., Schmolke, M., Mesterhazy, A. and Nicholson, P. 2007. Identification of QTLs for resistance to Fusarium head blight, DON accumulation and associated traits in the winter wheat variety Arina. Theor. Appl. Genet. 115:617-625.

Edwards, S. G., Imathiu, S. M., Ray, R. V., Back, M. and Hare, M. C. 2012. Molecular studies to identify the Fusarium species responsible for HT-2 and T-2 mycotoxins in UK oats. Int. J. Food Microbiol. 156:168-175.

Emel, S. 2010. Evaluation of ISSR markers to assess genetic variability and relationship among winter triticale $(\times$ Triticosecale Wittmack) cultivar. Pak. J. Bot. 42:2755-2763.

Fernández, E., Figueiras, M. and Benito, C. 2002. The use of ISSR and RAPD markers for detecting DNA polymorphism, genotype identification and genetic diversity among barley cultivars with known origin. Theor. Appl. Genet. 104:845851. 
Foroud, N. A. and Eudes, F. 2009. Trichothecenes in cereal grains. Int. J. Mol. Sci. 10:147-173.

Gautam, P. and Dill-Macky, R. 2012. Free water can leach mycotoxins from Fusarium-infected wheat heads. J. Phytopathol. 160:484-490.

Gervais, L., Dedryver, F., Morlais, J.-Y., Bodusseau, V., Negre, S., Bilous, M., Groos, C. and Trottet, M. 2003. Mapping of quantitative trait loci for field resistance to Fusarium head blight in an European winter wheat. Theor. Appl. Genet. 106:961-970.

Goliński, P., Perkowski, J., Kostecki, M., Grabarkiewicz-Szczęsna, J. and Chełkowski, J. 1996. Fusarium species and Fusarium toxins in wheat in Poland - a comparison with neighbour countries. Sydowia 48:12-22.

Góral, T., Ochodzki, P., Walentyn-Góral, D. and Justesen, A. F. 2011. Fusarium species and Fusarium mycotoxins in grain of winter wheat in Poland in 2010. Conference Abstracts, 33rd Mycotoxin Workshop, Freising, Germany, 30th May - 1st June, $96 \mathrm{p}$.

Góral. T., Ochodzki. P., Walentyn-Góral. D., Nielsen. L. K., Justesen, A. F. and Jørgensen L. N. 2012. Effect of pre-crop and weather conditions on infection of heads of spring wheat with Fusarium fungi and content of mycotoxins in grain. Biul IHAR 265:11-21. (in Polish)

Gunnaiah, R., Kushalappa, A. C., Duggavathi, R., Fox, S. and Somers, D. J. 2012. Integrated metabolo-proteomic approach to decipher the mechanisms by which weat QTL (Fhbl) contributes to resistance against Fusarium graminearum. PLoS ONE 7(7):e40695. doi:10.1371/journal.pone.0040695.

Hai, L., Wagner, C. and Friedt, W. 2007. Quantitative structure analysis of genetic diversity among spring bread wheats (Triticum aestivum L.) from different geographical regions. Genetica 130:213-225.

Handa, H., Namiki, N., Xu, D. and Ban, T. 2008. Dissecting of the FHB resistance QTL on the short arm of wheat chromosome 2D using a comparative genomic approach: from QTL to candidate gene. Mol. Breed. 22:71-84.

Holzapfel, J., Voss, H.-H., Miedaner, T., Korzun, V., Häberle, J., Schweizer, G., Mohler, V., Zimmermann, G. and Hartl, L. 2008. Inheritance of resistance to Fusarium head blight in three European winter wheat populations. Theor. Appl. Genet. 117:1119-1128

Horevaj, P., Gale, L. and Milus, E. 2011. Resistance in winter wheat lines to initial infection and spread within spikes by deoxynivalenol and nivalenol chemotypes of Fusarium graminearum. Plant Dis. 95:31-33.

Kokkonen, M., Jestoi, M. and Laitila, A. 2012. Mycotoxin production of Fusarium langsethiae and Fusarium sporotrichioides on cereal-based substrates. Mycotoxin Res. 28:25-35.

Kollers, S., Rodemann, B., Ling, J., Korzun, V., Ebmeyer, E., Argillier, O., Hinze, M., Plieske, J., Kulosa, D., Ganal, M. W. and Röder, M. S. 2013. Whole genome association mapping of Fusarium head blight resistance in European winter wheat (Triticum aestivum L.). PLoS ONE 8:e57500.

Kriss, A. B., Paul, P. A., Xu, X., Nicholson, P., Doohan, F. M.,
Hornok, L., Rietini, A., Edwards, S. G. and Madden, L. V. 2012. Quantification of the relationship between the environment and Fusarium head blight, Fusarium pathogen density, and mycotoxins in winter wheat in Europe. Eur. J. Plant Pathol. 133:975-993.

Kumaraswamy, G. K., Bollina, V., Kushalappa, A. C., Choo, T. M., Dion, Y., Rioux, S., Mamer, O. and Faubert, D. 2011. Metabolomics technology to phenotype resistance in barley against Gibberella zeae. Eur. J. Plant Pathol. 130:29-43.

Lemmens, M., Buerstmayr, H., Krska, R., Schuhmacher, R., Grausgruber, H. and Ruckenbauer, P. 2004. The effect of inoculation treatment and long-term application of moisture on Fusarium head blight symptoms and deoxynivalenol contamination in wheat grains. Eur. J. Plant Pathol. 110:299-308.

Lemmens, M., Scholz, U., Berthiller, F., Dall'Asta, C., Koutnik, A., Schuhmacher, R., Adam, G., Buerstmayr, H., Mesterházy, A., Krska, R. and Ruckenbauer, P. 2005. The ability to detoxify the mycotoxin deoxynivalenol colocalizes with a major quantitative trait locus for Fusarium head blight resistance in wheat. Mol. Plant Microbe Interact. 18:1318-1324.

Lemmens, M., Koutnik, A., Steiner, B., Buerstmayr, H., Berthiller, F., Schuhmacher, R., Maier, F. and Schäfer, W. 2008. Investigations on the ability of $F h b 1$ to protect wheat against nivalenol and deoxynivalenol. Cereal Res. Commun. 36:429-435.

Leplat, J., Friberg, H., Abid, M. and Steinberg, C. 2013. Survival of Fusarium graminearum, the causal agent of Fusarium head blight. A review. Agron. Sustain. Dev. 33:97-111.

Łukanowski, A., Lenc, L. and Sadowski, C. 2008. First report on the occurrence of Fusarium langsethiae isolated from wheat kernels in Poland. Plant Dis. 92:488-488.

Maric, S., Bolaric, S., Martincic, J., Pejic, I. and Kozumplik, V. 2004. Genetic diversity of hexaploid wheat cultivars estimated by RAPD markers, morphological traits and coefficients of parentage. Plant Breed. 123:366-369.

Mesterhazy, A. 1995. Types and components of resistance to Fusarium head blight of wheat. Plant Breed. 114:377-386.

Mesterházy, A. 2002. Role of deoxynivalenol in aggressiveness of Fusarium graminearum and F. culmorum and in resistance to Fusarium head blight. Eur. J. Plant Pathol. 108:675-684.

Mesterhazy, A. 2002. Theory and practice of the breeding for Fusarium head blight resistance in wheat. J. Appl. Genet. 43A:289-302.

Mesterhazy, A., Bartok, T., Mirocha, C. G. and Komoroczy, R. 1999. Nature of wheat resistance to Fusarium head blight and the role of deoxynivalenol for breeding. Plant Breed. 118:97110 .

Mesterhazy, A., Toth, B. and Kaszonyi, G. 2006. Sources of "environmental interactions" in phenotyping and resistance evaluation ways to neutralize them. In: The global Fusarium initiative for international collaboration - strategic planning workshop held at CIMMYT. eds. by T. Ban, J. M. Lewis, E. E. Phipps, pp. 84-92. El Batan, Mexico.

Mesterházy, A., Tóth, B., Bartók, T. and Varga, M. 2008. Breeding strategies against FHB in winter wheat and their relation 
to type I resistance. Cereal Res. Commun. 36:37-43.

Miedaner, T. 1997. Breeding wheat and rye for resistance to $F u$ sarium diseases. Plant Breed. 116:201-220.

Miedaner, T., Moldovan, M. and Ittu, M. 2003. Comparison of spray and point inoculation to assess resistance to Fusarium head blight in a multienvironment wheat trial. Phytopathology 93:1068-1072.

Miedaner, T. and Perkowski, J. 1996. Correlations among Fusarium culmorum head blight resistance, fungal colonization and mycotoxin contents in winter rye. Plant Breed 115:347351.

Miedaner, T. and Reinbrecht, C. 2001. Trichothecene content of rye and wheat genotypes inoculated with a deoxynivalenoland a nivalenol-producing isolate of Fusarium culmorum. $J$. Phytopathol. 251:245-251.

Miedaner, T. and Voss, H. H. 2008. Effect of dwarfing Rht genes on Fusarium head blight resistance in two sets of near-isogenic lines of wheat and check cultivars. Crop Sci. 48:21152122.

Miedaner, T., Würschum, T., Maurer, H. P., Korzun, V., Ebmeyer, E. and Reif, J. C. 2011. Association mapping for Fusarium head blight resistance in European soft winter wheat. Mol. Breed. 28:647-655.

Miller, J. D. 2008. Mycotoxins in small grains and maize: old problems, new challenges. Food Addit. Contam. 25:219-230.

Miller, J. D. 1994. Epidemiology of Fusarium ear diseases of cereals. In: Mycotoxins in Grain: Compounds Other than Aflatoxins, eds. by J. D. Miller, H. L. Trenholm, pp. 19-36. Eagan Press, St Paul, MN, USA.

Miller, J. D. and Arnison, P. G. 1986. Degradation of deoxynivalenol by suspension cultures of the Fusarium head blight resistant wheat cultivar Frontana. Can. J. Plant. Pathol. 8:147150.

Mitrofanova, O. P., Strelchenko, P. P., Konarev, A. V. and Balfourier, F. 2009. Genetic differentiation of hexaploid wheat inferred from analysis of microsatellite loci. Russ. J. Genet. 45:1351-1359.

Moreno, S., Martin, J. and Ortiz, J. 1998. Inter-simple sequence repeats PCR for characterization of closely related grapevine germplasm. Euphytica 101:117-125.

Najaphy, A., Parchin, R. A. and Farshadfar, E. 2011. Evaluation of genetic diversity in wheat cultivars and breeding lines using inter simple sequence repeat markers. Biotechnol. Biotechnol. Equip. 25:2634-2638.

Nicholson, P., Bayles, R. and Jennings, P. 2008. Understanding the basis of resistance to Fusarium head blight in UK winter wheat (REFAM). Project Report No. 432; HGCA Agriculture and Horticulture Development Board, Stoneleigh Park, Kenilworth, Warwickshire, UK.

Nielsen, L. K., Jensen, J. D., Rodríguez, A., Jørgensen, L. N. and Justesen, A. F. 2012. TRI12 based quantitative real-time PCR assays reveal the distribution of trichothecene genotypes of $F$. graminearum and F. culmorum isolates in Danish small grain cereals. Int. J. Food Microbiol. 157:384-392.
Ochodzki, P. and Góral, T. 2006. Production of mycotoxins by selected Fusarium graminearum and F. culmorum isolates cultured on rice and wheat. Conference Papers of 28. Mykotoxin-Workshop, Bydgoszcz, Poland, 29-31 May, 73 p.

Perkowski, J., Buśko, M., Stuper, K., Kostecki, M., Matysiak, A. and Szwajkowska-Michałek, L. 2008. Concentration of ergosterol in small-grained naturally contaminated and inoculated cereals. Biologia 63:542-547.

Perkowski, J., Kiecana, I., Stachowiak, J. and Basiński, T. 2003. Natural occurrence of scirpentriol in cereals in infected by Fusarium species. Food Addit. Contam. 20:572-578.

Perkowski, J., Plattner, R. D., Goliński, P., Vesonder, R. F. and Chełkowski, J. 1990. Natural occurrence of deoxynivalenol, 3-acetyl-deoxynivalenol, 15-acetyl-deoxynivalenol, nivalenol, 4,7-dideoxynivalenol, and zearalenone in Polish wheat. Mycotoxin Res. 6:7-12.

Perkowski, J., Stachowiak, J., Kiecana, I., Goliński, P. and Chełkowski, J. 1997. Natural occurrence of Fusarium mycotoxins in Polish cereals. Cereal Res. Commun. 25:379-380.

Perkowski, J., Wiwart, M., Buśko, M., Laskowska, M., Berthiller, A., Kandler, S. and Krska, R. 2007. Fusarium toxins and total fungal biomass indicators in naturally contaminated wheat samples from north-eastern Poland in 2003. Food Addit. Contam. 24:1292-1298.

Reddy, M. P., Sarla, N. and Siddiq, E. A. 2002. Inter simple sequence repeat (ISSR) polymorphism and its application in plant breeding. Euphytica 128:9-17.

Roldan-Ruiz, I., Dendauw, J., Van Bockstaele, E., Depicker, A. and De Loose, M. 2000. AFLP markers reveal high polymorphic rates in ryegrasses (Lolium spp.). Mol. Breed. 6:125-134.

Rutkoski, J., Benson, J., Jia, Y., Brown-Guedira, G., Jannink, J.L. and Sorrells, M. 2012. Evaluation of genomic prediction methods for Fusarium head blight resistance in wheat. Plant Genome J. 5:51.

Schlüter, P. and Harris, S. 2006. Analysis of multilocus fingerprinting data sets containing missing data. Mol. Ecol. Notes 6:569-572.

Schmolke, M., Zimmermann, G., Schweizer, G., Miedaner, T., Korzun, V., Ebmeyer, E. and Hartl, L. 2008. Molecular mapping of quantitative trait loci for field resistance to Fusarium head blight in a European winter wheat population. Plant Breed. 127:459-464.

Schollenberger, M., Drochner, W. and Müller, H.-M. 2007. Fusarium toxins of the scirpentriol subgroup: a review. Mycopathologia 164:101-118.

Schollenberger, M., Mueller, H. M., Ruefle, M., Suchy, S., Plank, S. and Drochner, W. 2006. Natural occurrence of $16 \mathrm{Fu}$ sarium toxins in grains and feedstuffs of plant origin from Germany. Mycopathologia 161:43-52.

Schroeder, H. W. and Christiansen, J. J. 1963. Factors affecting resistance of wheat to scab caused by Gibberella zeae. Phytopathology 53:831-838.

Schuster, R. and Ellner, F. M. 2008. Level of Fusarium infection in wheat spikelets related to location and number of inocu- 
lated spores. Mycotoxin Res. 24:80-87.

Sears, E. R. 1981. Transfer of alien genetic material to wheat. In: Wheat science today and tomorrow, eds. by L. T. Evan, W. J. Peacock, pp. 75-89. Cambridge University Press Cambridge.

Shen, J., Ding, X., Liu, D., Ding, G., He, J., Li, X., Tang, F. and Chu, B. 2006. Intersimple sequence repeats (ISSR) molecular fingerprinting markers for authenticating populations of Dendrobium officinale Kimura et Migo. Biol. Pharm. Bull. 29: 420-422.

Skinnes, H., Semagn, K., Tarkegne, Y., Marøy, A. G. and Bjørnstad, A. 2010. The inheritance of anther extrusion in hexaploid wheat and its relationship to Fusarium head blight resistance and deoxynivalenol content. Plant Breed. 129:149-155.

Snijders, C. H. A. and Kretching, C. F. 1992. Inhibition of deoxynivalenol translocation and fungal colonization in Fusarium head blight resistant wheat. Can. J. Bot. 70:1570-1576.

Snijders, C. H. A. and Perkowski, J. 1990. Effects of head blight caused by Fusarium culmorum on toxin content and weight of wheat kernels. Phytopathology 80:566-570.

Srinivasachary, Gosman, N., Steed, A., Hollins, T. W., Bayles, R., Jennings, P. and Nicholson, P. 2009. Semi-dwarfing Rht-B1 and Rht-D1 loci of wheat differ significantly in their influence on resistance to Fusarium head blight. Theor. Appl. Genet. 118:695-702.

Stenglein, S. A. 2009. Fusarium poae: a pathogen that needs more attention. J. Plant Pathol. 91:25-36.

Stępień, Ł., Mohler, V., Bocianowski, J. and Koczyk, G. 2007. Assessing genetic diversity of Polish wheat (Triticum aestivum) varieties using microsatellite markers. Genet. Res. Crop Evol. 54:1499-1506.

Stępień, Ł., Popiel, D., Koczyk, G. and Chełlkowski, J. 2008. Wheat-infecting Fusarium species in Poland-their chemotypes and frequencies revealed by PCR assay. J. Appl. Genet. 49:433-441.

Tamburic-Ilincic, L., Falk, D. and Schaafsma, A. 2011. Fusarium ratings in Ontario Winter Wheat Performance Trial (OWWPT) using an index that combines Fusarium head blight symptoms and deoxynivalenol levels. Czech. J. Genet. Plant Breed. 47:S115-S122.

Tams, S. H., Bauer, E., Oettler, G. and Melchinger, A. E. 2004. Genetic diversity in European winter triticale determined with SSR markers and coancestry coefficient. Theor. Appl. Genet. 108:1385-1391.

Thomas, K. and Bebeli, P. 2010. Genetic diversity of Greek Aegilops species using different types of nuclear genome markers. Mol. Phylogenet. Evol. 56:951-961.

Thrane, U., Adler, A., Clasen, P.-E., Galvano, F., Langseth, W., Lew, H., Logrieco, A., Nielsen, K. F. and Ritieni, A. 2004. Diversity in metabolite production by Fusarium langsethiae, Fusarium poae, and Fusarium sporotrichioides. Int. J. Food Microbiol. 95:257-266.

Tóth, B., Kaszonyi, G., Bartok, T., Varga, J. and Mesterhazy, A. 2008. Common resistance of wheat to members of the Fusar- ium graminearum species complex and $F$. culmorum. Plant Breed. 127:1-8.

van de Wouw, M., van Hintum, T., Kik, C., van Treuren, R. and Visser, B. 2010. Genetic diversity trends in twentieth century crop cultivars: a meta-analysis. Theor. Appl. Genet. 120:1241-1252.

Van Ginkel, M. and Gilchrist, L. 2002. How to make intelligent crosses to accumulate Fusarium head blight resistance genes based on knowledge of the underlying resistance mechanisms. In: Proceedings of the 2002 National Fusarium Head Blight Forum, ed. by Canty, S. M. et al. pp. 268-272. Erlanger, KY. 7-9 Dec. 2002, Michigan State University, East Lansing. MI, USA.

Vogelgsang, S., Sulyok, M., Hecker, A., Jenny, E., Krska, R., Schuhmacher, R. and Forrer, H.-R. 2008. Toxigenicity and pathogenicity of Fusarium poae and Fusarium avenaceum on wheat. Eur. J. Plant Pathol. 122:265-276.

Voss, H.-H., Holzapfel, J., Hartl, L., Korzun, V., Rabenstein, F., Ebmeyer, E., Coester, H., Kempf, H. and Miedaner, T. 2008. Effect of the Rht-D1 dwarfing locus on Fusarium head blight rating in three segregating populations of winter wheat. Plant Breed. 127:333-339.

Wang, Y. Z. and Miller, J. D. 1988. Screening techniques and sources of resistance to Fusarium head blight. In: Wheat production constraints in tropical environments, ed. by A. R. Klatt, pp. 239-250. CIMMYT, Mexico, DF.

Wiśniewska, H. and Kowalczyk, K. 2005. Resistance of cultivars and breeding lines of spring wheat to Fusarium culmorum and powdery mildew. J. Appl. Genet. 46:35-40.

Würschum, T., Langer, S. M., Longin, F. H., Korzun, V., Akhunov, E., Ebmeyer, E., Schachschneider, R., Schacht, J., Kazman, E. and Reif, J. C. 2013. Population structure, genetic diversity and linkage disequilibrium in elite winter wheat assessed with SNP and SSR markers. Theor. Appl. Genet. 126:1477-1486.

Xu, X. M., Monger, W., Ritieni, A. and Nicholson, P. 2007. Effect of temperature and duration of wetness during initial infection periods on disease development, fungal biomass and mycotoxin concentrations on wheat inoculated with single, or combinations of, Fusarium species. Plant Pathol. 56:943-956.

Yan, W., Li, H. B., Cai, S. B., Ma, H. X., Rebetzke, G. J. and Liu, C. J. 2011. Effects of plant height on type I and type II resistance to Fusarium head blight in wheat. Plant Pathol. 60:506-512.

Zeb, B., Khan, I. A., Ali, S., Bacha, S., Mumtaz, S. and Swati, Z. A. 2009. Study on genetic diversity in Pakistani wheat varieties using simple sequence repeat (SSR) markers. Afr. J. Biotechnol. 8:4016-4019.

Zhang, L. Y., Liu, D. C., Guo, X. L., Yang, W. L., Sun, J. Z., Wang, D. W., Sourdille, P. and Zhang, A. M. 2011. Investigation of genetic diversity and population structure of common wheat cultivars in northern China using DArT markers. $B M C$ genetics 12:42. 